\title{
IV Congresso Sul-Brasileiro de Medicina do Esporte
}

\author{
1,2 e 3 de agosto de 2002 - Blumenau, SC \\ RESUMOS
}

\begin{abstract}
TRPO-01 PERFIL DE UM GRUPO DE CORONARIOPATAS PARTICIPANTES DE UM PROGRAMA DE PREVENÇÃO SECUNDÁRIA DA REGIÃO DE BLUMENAU

Kowalsky D., Giacomet M., Karsten M.

Universidade do Vale do Itajaí, Itajaí, SC, Brasil
\end{abstract}

Uma das maiores preocupações da atualidade, em relação à saúde, tem sido o aumento da incidência das doenças cardiovasculares. Com altos índices de morbimortalidade, estas doenças estão relacionadas a inúmeros fatores de risco, classificados em não modificáveis, como idade e sexo, e em modificáveis, como o tabagismo, a hipertensão arterial e a obesidade. Um outro grande fator contribuinte para o surgimento das doenças cardiovasculares é o sedentarismo associado a uma vida estressante. Após a ocorrência de um infarto, uma cirurgia de revascularização miocárdica ou angioplastia, o indivíduo deve se submeter a um programa adequado de reabilitação cardíaca (prevenção secundária), para que possa retornar ao seu trabalho e às suas atividades de vida diária no menor tempo possível. A Fisioterapia, aliada a uma equipe multidisciplinar, tem uma fundamental importância na reabilitação do indivíduo, tanto na fase hospitalar, quanto na fase ambulatorial, promovendo a prevenção secundária. Sua atuação ocorre através da execução de exercícios físicos e de orientações dadas ao paciente em relação aos seus hábitos de vida, como tabagismo e sedentarismo. Este trabalho teve por objetivo verificar o perfil dos participantes do programa de prevenção secundária, vinculado a um hospital da região de Blumenau, SC quanto à presença de fatores de risco para coronariopatias, a mudança de hábitos de vida e aspectos sociais. Os dados foram obtidos através da aplicação de um formulário sobre os hábitos de vida a 41 participantes do programa nos meses de dezembro de 1999 e março de 2000. Os resultados foram satisfatórios quanto à prática de exercícios pós evento $(82,9 \%)$, houve redução do nível de colesterol LDL $(55,8 \%)$, melhora na convivência familiar (56\%) e um retorno às atividades laborais da maioria $(70,5 \%)$, demonstrando que a reabilitação secundária pode ajudar o paciente a recuperar-se de forma adequada, se este for devidamente aconselhado e acompanhado.

TRPO-02 AVALIAÇÃO DO CONHECIMENTO NUTRICIONAL DE BEBIDAS ENERGÉTICAS POR PRATICANTES DE ATIVIDADE FÍSICA EM UMA ACADEMIA DE GINÁSTICA EM SÃO PAULO

Dall' Agnol T.M, Di Ciero P., Botelho P.A.

D’Agnol Consultoria em Nutrição e Saúde, São Paulo - S.P., Brasil

Objetivo: Avaliar o conhecimento nutricional sobre bebidas energéticas na saúde e performance - além de obter informações sobre mitos relacionados às mesmas - por esportistas de uma academia. Método: Foi aplicado um questionário com perguntas fechadas, elaborado por nutricionistas, para 91 alunos. Os dados foram tabulados no programa EPI-INFO 6. Resumo dos resultados: A maioria da amostra desconhece a finalidade das bebidas energéticas $(n=76$; $60 \%)$ e afirma que as mesmas podem provocar taquicardia $(n=52$;
$57 \%)$ e não auxiliam na eliminação de toxinas $(n=54 ; 59 \%)$, porém tem conhecimento que as mesmas não possuem álcool $(n=75 ; 82 \%)$. Da amostra estudada, 69\%, 52\% e 60\% demonstram desconhecimento sobre a presença de vitaminas, auxílio na prática esportiva e na concentração mental, respectivamente. Conclusões: $O$ trabalho demonstrou um grande desconhecimento sobre os componentes de bebidas energéticas e seus benefícios nutricionais. Há necessidade de maior esclarecimento e orientação sobre os componentes destas bebidas e seus benefícios físicos e mentais no organismo.

\section{TRPO-03 ESTUDO DO PADRÃO ELETROMIOGRÁ- FICO DOS MÚSCULOS RETO FEMORAL, BÍCEPS FE- MORAL, GLÚTEO MÁXIMO E GASTROQUINEMIO LATERAL EM EXERCÍCIO NO LEG-PRESS $\mathbf{4 5}^{\circ}$. ES- TUDO PILOTO}

Gress F.A.G., Melo S.I.L., Borges Junior N.G., Bertoni A., Leite R.M.

Laboratório de Pesquisa em Biomecânica Aquática, Centro de Educação Física e Desporto, Universidade do Estado de Santa Catarina, Florianópolis, SC, Brasil

Este estudo teve por objetivo analisar as curvas dos sinais eletromiográficos dos músculos reto femoral (RF), bíceps femoral (BF), glúteo máximo $(\mathrm{GM})$ e gastroquinêmio lateral $(\mathrm{GL})$ durante exercício no leg press $45^{\circ}$. Foi sujeito desse estudo um indivíduo do sexo masculino, com idade de 29 anos e estatura de 1,87 metros. Foram usados eletrodos bipolares colocados sobre a pele na região central do ventre do músculo paralelamente as fibras musculares. A pele sob os eletrodos foi preparada primeiramente por uma depilação e posterior assepsia. O eletrodo de aterramento foi colocado na pele sobre o côndilo femoral. Para a aquisição dos sinais EMGs foi utilizado o eletromiografo do tipo DATALOGGER de oito canais onde foram utilizados apenas 4 canais com freqüência de aquisição de $1.000 \mathrm{~Hz}$ por canal. O exercício de extensão de joelhos e quadril foi realizado em um aparelho Leg Press 45 graus. O teste foi executado com uma carga de 588N. O indivíduo executou um ciclo do exercício, partindo da posição inicial com joelho flexionado à $90^{\circ}$, era feita então a extensão de joelho e quadril. A captação do sinal foi feita nas fases concêntrica e excêntrica da atividade. Analisando os dados pode-se notar que os músculos RF, BF e GM, estão ativados no início da extensão dos joelhos e quadril, ou seja, na contração concêntrica. A literatura consultada relata que um sinal EMG maior no RF e GM um pouco menor, para o inicio da extensão de quadril e joelho, concordando assim com os dados coletados neste estudo. Os músculos RF e BF diminuem a sua atividade com o aumento do ângulo da articulação do joelho e quadril, ao passo que o GM e GL aumentam suas atividades, o contrário deste evento ocorre na contração excêntrica, onde o GM e GL ficam com sua atividade reduzida. À medida que ocorre a extensão de joelho e quadril há um aumento na amplitude do sinal EMG do músculo glúteo máximo. Ocorre um aumento do sinal EMG no músculo gastrocnêmio lateral ao final do movimento, ou seja, na extensão total dos joelhos. Observa-se que os 
músculos, reto femoral e bíceps femoral estão ativos nas fases concêntrica e excêntrica do movimento, diminuindo sua atividade ao final da contração.

\section{TRPO-06 ADAPTAÇÕES NEUROMUSCULARES E MORFOLÓGICAS DE MENINOS SUBMETIDOS A UM PROGRAMA DE TREINAMENTO DE FORÇA}

Sant' Anna M.M., Collet C., Bos C., Bohn L., Oliveira N., Castillo R., Pinto R.S., Oliveira A.R.

Universidade Federal do Rio Grande do Sul, Porto Alegre, RS, Brasil

Objetivo: Investigar os efeitos de um programa de treinamento de força sobre a força dinâmica máxima, massa magra e massa de gordura corporal de meninos. Método: Dezoito meninos saudáveis (1012 anos), alunos do Colégio Militar de Porto Alegre, voluntariamente participaram do grupo experimental ou controle após os pais estarem cientes dos procedimentos do estudo e assinarem um termo de consentimento. As sessões do programa de treinamento de força tiveram duração de $60 \mathrm{~min}$, executadas três vezes por semana, durante 12 semanas. A força dinâmica máxima foi avaliada pelo teste de 1 repetição máxima (1-RM) nos exercícios de flexão do cotovelo e extensão do joelho. A massa magra e massa de gordura corporal foram avaliadas pela absortometria radiológica de dupla energia (DXA) através de exame de corpo inteiro. Para análise dos resultados intragrupo foi utilizado o teste $t$ de Student para dados pareados. Valores de delta (D) e o teste t de Student para dados independentes foram utilizados para a análise estatística intergrupo. O índice de significância adotado foi $\mathrm{p}<0,05$. Resultados: Após o período do programa de treinamento, houve aumento na força dinâmica máxima intragrupo. Entretanto, o aumento na força do grupo experimental foi maior que o grupo controle. Não houve diferença no aumento da massa magra intergrupo. $\mathrm{O}$ grupo experimental manteve a massa de gordura corporal, enquanto que o grupo controle apresentou aumento após o período de treinamento. Conclusões: O programa de treinamento de força promoveu aumento na força dinâmica máxima e manutenção da massa de gordura corporal. Não houve alteração da massa magra dos meninos induzida pelo treinamento de força.

\section{TRPO-07 A INFLUÊNCIA DO EXERCÍCIO FÍSICO REGULAR NA GLICEMIA DO INDIVÍDUO DIABÉTI- CO TIPO 2}

Silva C.A. ${ }^{2,3}$, Lima W.C. ${ }^{1}$, Serafim M. ${ }^{3}$, Porto M. ${ }^{3}$

1-Universidade do Estado de Santa Catarina-UDESC, Centro de Educação Física, Fisioterapia e Desportos-CEFID, Florianópolis, SC; 2-Universidade Regional de BlumenauFURB, Blumenau, SC; 3-Setor de Prevenção e Reabilitação Cardiovascular - Unicardio/HSC, Blumenau, SC

O objetivo do estudo foi analisar o efeito do exercício físico regular no indivíduo diabético tipo 2 , tratado e não-tratado com insulina, em indivíduos do Setor de Prevenção e Reabilitação Cardiovascular Unicardio/HSC, Blumenau, Santa Catarina. Foram realizados testes de glicemia jejum, hemoglobina glicosilada e lipídios plasmáticos (C-Total, HDL-C, LDL-C e TRIG), em uma amostra de 33 indivíduos, que realizaram um programa de exercício físico de 10 semanas, sendo posteriormente reavaliados. Os instrumentos utilizados foram: o exame de sangue em jejum laboratorial para medir a glice- mia em jejum, a hemoglobina glicosilada e os lipídios plasmáticos. Como análise estatística, utilizou-se o Teste " $\mathrm{t}$ " de Student. Como resultados da pesquisa, obteve-se os seguintes dados: Hemoglobina Glicosilada média pré-teste $=9,50 \%$ e pós-teste $=8,49 \%$; Glicemia de Jejum média pré-teste $=164,75 \mathrm{mg} / \mathrm{dL}$ e pós-teste $=156,35 \mathrm{mg} /$ dL; Lipídios Plasmáticos (C-Total média pré-teste $=221,48 \mathrm{mg} / \mathrm{dL}$ e pós-teste $=212,54 \mathrm{mg} / \mathrm{dL} ;$ LDL-C média pré-teste $=56,97 \mathrm{mg} / \mathrm{dL}$ e pós-teste $=148,14 \mathrm{mg} / \mathrm{dL} ;$ HDL-C média pré-teste $=40,45 \mathrm{mg} / \mathrm{dl}$ e pós-teste $=44,75 \mathrm{mg} / \mathrm{dL} ;$ TRIG média pré-teste $=203,09 \mathrm{mg} / \mathrm{dL}$ e pós-teste $=162,60 \mathrm{mg} / \mathrm{dl}$ ). Estes resultados permitem concluir que o exercício físico é de grande importância no tratamento do diabetes mellitus tipo 2, diminuindo e controlando a glicemia desse tipo de indivíduo.

Unitermos: exercício físico, glicemia, hemoglobina glicosilada, lipídios plasmáticos, diabetes mellitus tipo 2 .

\section{TRPO-08 AVALIAÇÃO DOS MARCADORES DE LE-} SÃO MUSCULAR EM ATLETAS

Petter L.P., Brum L.M., Petkowicz R., Oliveira J.

Grêmio Náutico União - Porto Alegre, RS, Brasil

1. Objetivo: Analisar os níveis séricos dos marcadores nas modalidades esportivas, comparar os níveis séricos das enzimas pré e pós treinamento e determinar qual o melhor marcador bioquímico de sobre caga muscular pós exercício físico. 2. Método: Foram analisadas amostras de sangue de 47 atletas distribuídos nos seguintes grupos: nadadores de piscina, nadadores de travessia, jogadores de vôlei e basquete. Os atletas que participaram do estudo, pertencem às equipes principais do Grêmio Náutico União e Clube Caixeiros Viajantes. As amostras de sangue foram obtidas através de punção venosa 10 minutos antes do exercício e 10 minutos após o exercício, no período do mesociclo. As dosagens foram realizadas no aparelho Hitachi 747, da Roche. Foram processados os seguintes ensaios: AST, LDH e CK. Para análise da diferença entre valores encontrados nos períodos pré e pós exercício foram utilizadas a análise de variância e a análise de variância múltipla. 3. Resultado: A AST não apresentou diferença significativa pré e pós exercício em nenhum dos grupos estudados. A DHL apresentou diferença significativa em nadadores de travessia. A CK apresentou diferença pré e pós exercício nos 4 grupos estudados, sendo que o vôlei foi o grupo que apresentou níveis séricos pós exercício mais elevados. 4. Conclusões: Através dessa pesquisa concluímos ser o CK o melhor parâmetro para avaliar a sobrecarga muscular pelo exercício, constituindo-se num indicador prático na triagem dos atletas que necessitam de uma avaliação clínica e laboratorial mais rigorosa e orientando o planejamento de um treinamento adequado e efetivo que respeite condições individuais. Seria interessante que os níveis de CK fossem determinados em intervalos de 6 horas e 18 horas após o término do exercício, pois encontraríamos taxas mais elevadas.

TRPO-09 FATORES DE MOTIVAÇÃO ENTRE INDIVÍDUOS ADULTOS PARA O ENGAJAMENTO EM UM PROGRAMA DE EXERCÍCIOS

Petkowicz R.O., Sousa L.B., Brescianini B., Chaves C., Silva A.C., Medaglia A., Santos H.F. Grêmio Náutico União - Porto Alegre, RS, Brasil

Introdução: Os riscos de saúde gerados pelo sedentarismo e benefícios do exercício para promoção da saúde são assuntos amplamente 
discutidos e divulgados tanto no meio médico como para a população em geral. Observa-se que o número de pessoas que aderem a programas de exercício com o objetivo de cuidar da saúde cresce anualmente. Objetivo: Identificar na população que procurou o Grêmio Náutico União para início de atividade física regular os fatores que os motivaram este início. Avaliar a associação entre atividade física na infância e a atividade física na vida adulta. Métodos: Durante a avaliação pré participação no programa de atividade física era questionado qual a motivação ou indicação para início do programa de exercício, cada participante poderia indicar mais de um fator, quando presente, e a prática de esportes regularmente durante a infância (extra curricular). Resultados: A amostra foi composta por 514 pessoas avaliadas num período de 6 meses. A idade média foi 39,2 anos, a distribuição por sexo foi de $31,9 \%$ masculino e $61,1 \%$ feminino, $68 \%$ da população foi classificada como previamente sedentários. Na distribuição dos motivos para iniciar atividade física deixar o sedentarismo foi o mais citado $(55,8 \%)$, as indicações médicas clínicas foi 7,3\% e ortopédicas 8,6\% das justificativas. Quanto a prática de esporte na infância ela foi presente em $66,1 \%$ do grupo e $21,78 \%$ destes apresentaram como motivação para a prática esportiva na vida adulta o fato de terem praticado esportes na infância. Para a confirmação destes dados foi aplicado teste do qui-quadrado que mostrou correlação. Conclusões: Concluímos que os riscos do sedentarismo estão levando um maior número de pessoas a buscar a prática esportiva regular e que a prática esportiva durante a infância é um fator de motivação importante para a continuidade na vida adulta.

\section{TRPO-10 LEVANTAMENTO DAS LESÕES ESPORTI- VAS TRATADAS NO DEPARTAMENTO DE FISIOTE- RAPIA EM UM CLUBE POLIESPORTIVO}

Petkowicz R., Ceccato J., Pacheco A.M., Silva B.A.S., Santos H.F., Pacheco I.

\section{Dep. Médico e Fisioterapia Grêmio Náutico União}

Este estudo tem como objetivo levantar as lesões tratadas no período dos últimos cinco anos no Departamento Médico e Fisioterapia do Clube Grêmio Náutico União, procurando identificar as lesões mais freqüentes que necessitaram tratamento fisioterápico. Foi realizada análise descritiva dos dados. Primeiramente os atletas eram avaliados por um médico que dado o diagnóstico realizava tratamento clínico e encaminhava para avaliação e tratamento fisioterápicos. Os dados coletados correspondem aos anos de 1997 a 2001. A amostra foi de 325 atletas, sendo $181(55,7 \%)$ sexo masculino e $144(44,3 \%)$ sexo feminino e a idade média de 16,39 anos $( \pm 5,85)$. Os atletas tratados pertenciam as seguintes modalidades esportivas: basquetebol, esgrima, ginástica olímpica, ginástica rítmica desportiva, natação, remo e voleibol. Foi encontradas uma freqüência de $126(38,8 \%)$ lesões tratadas entre atletas pertencentes ao voleibol, natação 67 atletas $(20,6 \%)$ e basquete 50 atletas $(15,4 \%)$. Os restantes das lesões $(33,2 \%)$ distribuem-se entre os demais esportes. O segmento corporal mais comprometido foi o tornozelo em 108 atletas $(33,2 \%)$, seguido por ombro em 46 atletas (14,2\%), coluna lombar e joelho 42 atletas $(12,9 \%)$ em cada segmento. Quando estratificado por modalidades esportivas encontramos o comprometimento do tornozelo no basquetebol, na esgrima, ginástica olímpica e vôlei em primeiro lugar. As estruturas mais comprometidos foram os ligamentos $(54,8 \%)$. O tipo de lesão mais freqüente foi entorse (36\%) seguido pelos pro- cessos inflamatórios $(17,2 \%)$. Sendo que os diagnósticos mais freqüentes foram entorse de tornozelo, instabilidade de ombro e lombalgia. Concluímos que o segmento mais lesado nas diferentes modalidades esportivas foi o tornozelo e a lesão mais frequiente o entorse. Os dados encontrados em nosso estudo estão de acordo com os dados apresentados na literatura onde o entorse é citado como lesão mais freqüente.

\section{TRPO-11 ASSOCIAÇÃO ENTRE LESÃO DE LCA E MEMBRO DOMINANTE}

Medaglia A., Chaves C., Rosa P., Santos H., Pacheco I.

Grêmio Náutico União - Porto Alegre, RS, Brasil

Introdução e objetivos: $\mathrm{O}$ ligamento cruzado anterior (LCA) é uma estrutura dinâmica em que sua maior função é ser restritor primário da subluxação anterior da tíbia, produz indo restrição secundária à rotação interna e valgo ou varo com o joelho em extensão. Juntamente com o cruzado posterior, serve de eixo para as rotações do joelho e colabora na flexão e extensão. As lesões do ligamento cruzado (LCA) anterior ocorrem mais freqüentemente em esportes com apoio do pé e rotações do joelho como no basquetebol, voleibol, futebol, ginástica, artes marciais, corridas entre outros. Com o objetivo de avaliar a relação entre o lado da lesão de LCA e o membro dominante foi realizado o presente estudo. Material e métodos: Foram realizadas entrevistas com pacientes que tiveram ruptura de LCA e foram submetidos a tratamento cirúrgico. Nas entrevistas procurou-se identificar membro em que ocorreu a lesão e membro dominante, mecanismo da lesão e ocorrência da lesão durante a prática esportiva. Os dados foram analisados através do pacote estatístico SPSS, sendo realizada estatística descritiva e teste do qui-quadrado. Resultados: O grupo estudado foi de 27 pacientes (96,3\% homens e $3,7 \%$ mulheres). A idade média dos pacientes, quando sofreram a lesão, foi de 29,5 anos. A distribuição entre os joelhos direito e esquerdo foi de $55,6 \%$ e $44,4 \%$, respectivamente, concordando com a literatura. Foi encontrado lado dominante direito em 77,8\% dos entrevistados. Em 77,8\% das lesões ocorreram durante a pratica esportiva e o futebol foi o esporte mais envolvido $(63 \%)$. Sendo que em $85 \%$ destas o paciente lesionou-se sozinho e o mecanismo da lesão mais freqüente foi apoio e giro do membro inferior. Foi realizado o teste de qui-quadrado para verificar a associação entre a presença de lesão de LCA e o membro dominante sendo encontrado um $\mathrm{p}=0,04$. Conclusões: As atividades esportivas estão presentes em uma alta porcentagem das ruptura de LCA, sendo o futebol o esporte mais envolvido. Encontramos associação entre lesão de LCA e o lado dominante.

\section{TRPO-12 PERFIL DA FORÇA EXPLOSIVA EM ATLE- TAS DE TRAMPOLIM ACROBÁTICO \\ * Siqueira O.D., ** Mello M.R., ** Faria C.C. \\ * UNISINOS, ULBRA-LAFIMED; ** ULBRA-LAFIMED. Email: odonizete@uol.com.br}

Objetivos: Descrever e comparar o perfil da força de membros inferiores no teste Squat Jump (SJ) e Countermovement (CMJ) dos atletas da modalidade de trampolim acrobático, em cada faixa etária, participantes do I Campeonato Brasileiro. Metodologia: Avaliou-se 33 atletas, do sexo feminino, com idades entre 9 e 12 anos, representantes de 9 estados brasileiros. As atletas realizaram dois testes de força explosiva dos membros inferiores: o Squat Jump (SJ) e Coun- 
termovement Jump (CMJ), em plataforma específica. Resultados: Os resultados demonstraram que o teste de $\mathrm{SJ}$ apresentou valores em centímetros, inferiores para todas as idades, quando comparados ao teste CMJ. No entanto, quando comparamos o teste SJ com o teste CMJ, foram encontradas diferenças significativas em relação as faixas etárias. Conclusão: Os resultados evidenciam que o perfil de força explosiva (SJ) em relação ao CMJ, parece ser um comportamento normal, devido a sua técnica de salto. Entretanto, nos parece que o comportamento das diferenças existentes entre os saltos nas diferentes faixas etárias, demonstram que a força muscular explosiva de membros inferiores, determinam uma resposta favorável com o passar dos anos para este grupo de atletas de trampolim acrobático.

\section{TRPO-13 PAPEL DO EXERCÍCIO NA MODULAÇÃO DO ESTRESSE OXIDATIVO NA INSUFICIÊNCIA CAR- DÍACA DIREITA}

Souza-Rabbo M.P., Silva L.F.F., Auzani J.A.S., Mazzotti N.G., Fernandes T.R.G., Belló-Klein A.

Laboratório de Fisiologia Cardiovascular - Depto de Fisiologia, ICBS, UFRGS

Objetivos: Avaliar o estresse oxidativo (EO) no tecido cardíaco de ratos com insuficiência cardíaca direita (ICD) submetidos a um programa de treinamento físico. Métodos: 32 ratos Wistar machos ( $160 \mathrm{~g}$ ) divididos em 4 grupos: Controle Sedentário (CS), Controle Treinado (CT), Insuficiente sedentário (IS) e Insuficiente treinado (IT). A ICD foi induzida pela droga Monocrotalina $(60 \mathrm{mg} / \mathrm{kg}$ i.p.). Treinamento: $1 \mathrm{~h}$ de corrida em esteira rolante à $0,9 \mathrm{~km} / \mathrm{h}(5 \mathrm{x}$ por semana) até quando os animais IT apresentassem incapacidade para a execução do protocolo ( $\cong 24$ dias). O EO cardíaco foi avaliado através da Quimiluminescência (QL) e da Capacidade Antioxidante Total (TRAP). As pressões ventriculares direita: diastólica final (PDFVD) e sistólica final (PSFVD), foram aferidas diretamente no ventrículo direito através de canulação da veia jugular direita sob anestesia de quetamina e xilazina. Resultados: 1) Os grupos IT e IS apresentaram hipertrofia do ventrículo direito em relação a CT e CS respectivamente. 2) O grupo IS apresentou aumento significativo de PDFVD em relação a CS. 3) Os grupos tratados tiveram um aumento significativo de PVDSF em relação aos controles. 4) O grupo IT apresentou QL aumentada em relação ao CT (31\%). 5) Os grupos IS e CT apresentaram aumento significativo no TRAP em relação ao CS de $42 \%$ e 35\%, respectivamente. Conclusões: Estes dados preliminares demonstram a eficiência do modelo de indução de ICD, assim como a aplicabilidade do protocolo de exercício. Podemos sugerir que tanto a monocrotalina quanto o exercício foram fatores estressantes suficientes para aumentar os AO não enzimáticos, mas que o exercício não foi capaz de evitar o dano oxidativo induzido pela insuficiência cardíaca.

\section{TRPO-14 PROCESSO DE SELEÇÃO DAS EQUIPES DE VOLEIBOL MASCULINAS DA SUPERLIGA}

Konrad L.M., Nascimento J.V., Barros M.V.G.

Universidade Federal de Santa Catarina, Florianópolis/SC, Brasil

Este estudo teve como objetivo analisar os fatores e indicadores de seleção utilizados por treinadores para a composição de equipes masculinas de voleibol de alto nível. Participaram do estudo 9 trei- nadores que dirigiram as equipes que disputaram a Superliga Nacional de Voleibol de 2000-2001. Foi utilizado um questionário adaptado de Silva (1996) que aborda os fatores antropométricos, condicionais, técnico-coordenativos, tático-cognitivos e psicológicos, além de indicadores de seleção para as posições de levantador (L), atacante de entrada (AE), atacante central (AC), atacante de saída (AS) e líbero (LB). Na análise foi empregada a estatística não-paramétrica contida no programa SPSS. Foi adotado um nível de significância de 0,05 para identificar diferenças significativas entre as variáveis do estudo. Os resultados da análise de variância de Kruskall-Wallis evidenciaram diferenças significativas entre funções dos jogadores nos fatores antropométricos e condicionais (AE, AC e AS), técnicocoordenativos (L e LB) e psicológicos (L). Para a seleção do levantador são necessárias capacidade de liderança e domínio da técnica de execução do toque de bola. Para AE são importantes o nível de força e domínio da técnica de execução da manchete. A altura, a envergadura e o comprimento de membros superiores e inferiores, bem como a técnica de execução da cortada são essenciais na seleção de AC. Já para o AS são utilizados a altura, nível de força e domínio da técnica de execução do bloqueio. Para o LB são considerados a capacidade de liderança e regularidade na execução dos fundamentos. Com relação aos procedimentos de seleção, a maioria dos treinadores considera inicialmente os recursos financeiros disponíveis, analisa a pontuação dos jogadores a partir do ranqueamento da $\mathrm{CBV}$ e, finalmente, observa os fatores de rendimento esportivo.

\section{TRPO-15 DETERMINANTES SOCIOECONÔMICOS DA PRÁTICA DE ATIVIDADES FÍSICAS DE LAZER EM UNIVERSITÁRIOS}

Konrad L.M., Acioly P.L., Barros M.V.G.

Núcleo de Pesquisa em Atividade Física \& Saúde - UFSC, Florianópolis-SC, Brasil

Este estudo epidemiológico descritivo (corte transversal) teve como objetivo identificar os determinantes socioeconômicos relacionados a prática de atividades físicas (AF) de lazer em universitários. Foi utilizada amostragem aleatória estratificada (erro amostral de 5\%; IC de 95\%) para selecionar uma amostra composta por 582 universitários. Para coleta dos dados (sociodemográficos e práticas de AF) utilizou-se um questionário administrado na forma de entrevista por telefone. Os dados foram analisados no programa SPSS, utilizandose estatística descritiva e teste de Qui-Quadrado. Para verificar as características das AF praticadas no tempo de lazer, utilizou-se a classificação em AF vigorosas, moderadas e caminhadas. Os estudantes gastam mais tempo (horas por semana) em AF vigorosas. Em geral, os homens despendem mais tempo em AF do que as mulheres. Os homens preferem as AF vigorosas enquanto que as mulheres mostram maior preferência por AF moderadas. A idade diferenciou significativamente o tempo despendido em caminhadas de lazer entre as mulheres e AF vigorosas entre os homens. A medida em que há um avanço na idade ocorre um decréscimo na prática de $\mathrm{AF}$ de lazer, tanto vigorosas quanto moderadas. A classe econômica diferenciou significativamente apenas o tempo despendido na realização de caminhadas de lazer. Os estudantes pertencentes à classe "A" são os que despendem maior tempo para a prática de AF de lazer, sejam elas vigorosas, moderadas ou caminhadas. Apenas entre as mulheres foram encontradas diferenças significativas no tempo despendido para $\mathrm{AF}$ vigorosas e caminhadas de lazer. As mulheres de 
nível socioeconômico mais alto apresentaram maior nível de prática de AF. Além disso, observou-se uma tendência de redução do nível de prática de $\mathrm{AF}$ de lazer conforme diminui o nível socioeconômico.

\section{TRPO-16 PREVALÊNCIA DE SOBREPESO E OBESI- DADE EM CRIANÇAS E ADOLESCENTES PRATI- CANTES DE FUTEBOL DE SALÃO}

Carvalho S.L.P., Lopes W.A., Carvalho S.P., Milano G.E., Dezan V.H., Sarraf T. Mendes R.A., Radominski R., Leite N. Núcleo de Pesquisa Qualidade de Vida, UFPR - Curitiba, PR $O$ objetivo foi identificar a prevalência de sobrepeso e obesidade em crianças e adolescentes praticantes de futebol de salão da Prefeitura de Curitiba. Estudo transversal e descritivo, utilizando-se como amostragem 97 meninos, de 8 a 15 anos $(11,73 \pm 1,5)$. Coletou-se dados pessoais, peso, estatura e perímetro braquial (PB). O Índice de Massa Corporal (IMC) foi utilizado conforme os critérios do CDC (2000): desnutrido < 5\%; normal 5-85\%; sobrepeso 85-95\%; obesidade > 95\%. O número de indivíduo nos percentis e os PB em valores médios e desvio padrão (dp) estão a seguir:

\begin{tabular}{c|c|c|c|c|c|c|c|c}
\hline \multirow{2}{*}{$\begin{array}{c}\text { Nutrição } \\
\text { Variáveis }\end{array}$} & \multicolumn{2}{|c|}{$\begin{array}{c}\text { Desnutrido } \\
<5 \%\end{array}$} & \multicolumn{2}{|c|}{$\begin{array}{c}\text { Normal } \\
5-85 \%\end{array}$} & \multicolumn{2}{c|}{$\begin{array}{c}\text { Sobrepeso } \\
85-95 \%\end{array}$} & \multicolumn{2}{|c}{$\begin{array}{c}\text { Obeso } \\
>95 \% .\end{array}$} \\
\cline { 2 - 9 } & $\mathrm{n}$ & $\%$ & $\mathrm{~N}$ & $\%$ & $\mathrm{~N}$ & $\%$ & $\mathrm{~N}$ & $\%$ \\
\hline IMC & 5 & 5,2 & 79 & 81,4 & 5 & 5,2 & 8 & 8,2 \\
PB $(\mathrm{cm})$ & $19,3 \pm 0,8$ & $20,9 \pm 1,8$ & $23,2 \pm 1,2$ & \multicolumn{2}{c}{$29,9 \pm 5,2$} \\
\hline
\end{tabular}

A soma dos percentuais de sobrepeso e obesidade superaram ao da desnutrição. Apesar disso, a prevalência de obesidade foi menor do que outras pesquisas, possivelmente pela prática de atividades físicas regulares, melhores hábitos alimentares, maior motivação e oportunidade de integração no grupo.

\section{TRPO-17 AMPLITUDE ARTICULAR, DESVIOS POS- TURAIS E DORES EM ATLETAS PRATICANTES DE HANDEBOL EM CURITIBA}

Sarraf T.A., Dezan V.H., Vialle C.D., Spinello A.P., Lopes W.A., Carvalho S., Milano G., Mendes R.A., Radominski R., Leite $\mathrm{N}$.

Núcleo de Pesquisa em Qualidade de Vida, UFPR, Curitiba, $P R$

Objetivo: Verificar a prevalência de dores articulares, desvios posturais na coluna vertebral e encurtamentos musculares em atletas de handebol. Metodologia: amostra com 12 atletas, integrantes da equipe masculina do Centro de Excelência de Handebol do Paraná, com idade média de 17,17 $\pm 0,83$ e IMC 23,22 $\pm 1,17$. Realizou-se anamnese, exame postural e provas musculares subjetivas. Resultados: As frequiências absolutas e relativas constam na tabela a seguir:

\begin{tabular}{lcc}
\hline Variáveis & n & \% \\
\hline Algias & 10 & 83,33 \\
Hiperlordose Cervical & 2 & 11,76 \\
Dorsocurvo & 7 & 41,18 \\
Hiperlordose Lombar & 8 & 47,06 \\
Encurtamento GM Ísquiostibiais & 4 & 30 \\
Encurtamento de M. Íliopsoas & 2 & 16,67 \\
Encurtamento de M. Reto Femoral & 11 & 91,67 \\
Encurtamento M. Peitoral Menor & 12 & 100 \\
Encurtamento M. Grande Dorsal & 9 & 75 \\
\hline
\end{tabular}

Conclusão: A maioria dos atletas apresentou algias, este resultado pode estar relacionado com a alta prevalência de desvios posturais encontrados (hiperlordose lombar e dorsocurvo) e a presença de desequilíbrios musculares, resultando em maior propensão a lesões. Os autores sugerem outros estudos abordando outras variáveis relacionadas com o surgimento de algias, como o excesso de volume de treinamento e a especialização precoce.

\section{TRPO-18 AMPLITUDES ARTICULARES EM CRIAN- ÇAS E ADOLESCENTES PRATICANTES DE FUTEBOL DE SALÃO}

Lopes W.A., Carvalho S.P., Milano G.E., Dezan V.H., Sarraf T.A., Radominski R., Mendes R.A., Leite N.

Núcleo de Pesquisa Qualidade de Vida, UFPR - Curitiba, PR

O objetivo foi avaliar a amplitude articular (AA) em crianças e adolescentes praticantes de futebol de salão da Prefeitura de Curitiba. Estudo transversal, descritivo e amostra dividida em: Grupo I, com 44 meninos < 12 anos e Grupo II, com 53 meninos $\geq 12$. Coletou-se dados pessoais, teste "sentar e alcançar" (TSA) e fleximetria de ombro (FO) e quadril (FQ) bilaterais. Classificou-se a AA, conforme os graus, em normal ou reduzida e o TSA com FQD. As médias (m) e desvios-padrão (dp) estão a seguir:

\begin{tabular}{|c|c|c|c|c|c|c|c|c|}
\hline & \multicolumn{4}{|c|}{ Grupo I } & \multicolumn{4}{|c|}{ Grupo II } \\
\hline & \multicolumn{2}{|c|}{ Normal } & \multicolumn{2}{|c|}{ Reduzida } & \multicolumn{2}{|c|}{ Normal } & \multicolumn{2}{|c|}{ Reduzida } \\
\hline & $\mathrm{n}$ & $m \pm d p$ & $\mathrm{n}$ & $\mathrm{m} \pm \mathrm{dp}$ & $\mathrm{n}$ & $m \pm d p$ & $\mathrm{n}$ & $\mathrm{m} \pm \mathrm{dp}$ \\
\hline $\mathrm{FO}(\mathrm{D})^{\mathrm{o}}$ & 33 & $185,6 \pm 5,2$ & 11 & $172 \pm 4,4$ & 28 & $188,1 \pm 5,9$ & 24 & $169,5 \pm 6,3$ \\
\hline $\mathrm{FO}(\mathrm{E})^{\mathrm{o}}$ & 29 & $187,4 \pm 5,9$ & 15 & $171,1 \pm 5,0$ & 31 & $187,4 \pm 6,0$ & 23 & $166,7 \pm 8,3$ \\
\hline $\mathrm{FQ}(\mathrm{D})^{\circ}$ & 23 & $87,4 \pm 8,4$ & 21 & $71,90 \pm 5,1$ & 19 & $85,8 \pm 5,8$ & 34 & $69,6 \pm 6,3$ \\
\hline $\mathrm{FQ}(\mathrm{E})^{\mathrm{o}}$ & 25 & $86,7 \pm 7,3$ & 19 & $68,84 \pm 6,8$ & 17 & $84,9 \pm 5,9$ & 36 & $66,5 \pm 8,5$ \\
\hline $\operatorname{TSA}(\mathrm{cm})$ & 23 & $24,2 \pm 5,9$ & 21 & $24,5 \pm 5,7 *$ & 19 & $21,52 \pm 6,8$ & 34 & $20,5 \pm 6,8^{*}$ \\
\hline
\end{tabular}

Os resultados demonstraram uma diminuição da AA com a idade e no TSA entre os grupos com AA reduzida $(\mathrm{p}<0,05)$. A menor AA pode estar associada a encurtamentos musculares e maiores possibilidades de lesões. Sugere-se exercícios de flexibilidade junto a este desporto para minimizar esses efeitos.

TRPO-19 DESVIOS POSTURAIS NA COLUNA VERTEBRAL EM CRIANÇAS E ADOLESCENTES PRATICANTES DE FUTEBOL DE SALÃO (FUTSAL)

Dezan V.H., Sarraf T.A., Lopes W.A., Carvalho S.L.P., Milano G.E., Mendes R.A., Radominski R.B., Leite N.

Núcleo de Pesquisa em Qualidade de Vida, UFPR, Curitiba, $P R$

Objetivo: Verificar a prevalência dos desvios posturais na coluna vertebral e sua associação com níveis de mobilidade articular em crianças e adolescentes praticantes de futsal. Metodologia: amostra com 97 meninos, divididos em: Grupo A $<12$ anos e Grupo B $\geq 12$ anos. Foram realizados exame postural, fleximetria, provas musculares e teste sentar e alcançar. Resultados: As médias e desvios padrões constam na tabela a seguir:

\begin{tabular}{lcc}
\hline Variável & Grupo A & Grupo B \\
\hline $\boldsymbol{n}$ & 44 & 53 \\
Idade Média & $10,34 \pm 0,78$ & $12,89 \pm 0,97 * *$ \\
IMC & $18,13 \pm 2,84$ & $18,64 \pm 3,62$ \\
Hiperlordose cervical & $11,36 \%$ & $18,87^{*}$ \\
Dorsocurvo & $0 \%$ & $13,2 \% * *$ \\
Hiperlordose lombar & $27,27 \%$ & $35,35 \%$ \\
Flexão Ombro Direito & $182,2 \pm 7,8$ & $179,5 \pm 11,2$ \\
Flexão Quadril Direito & $80 \pm 9,6$ & $75,4 \pm 9,9 *$ \\
Encurtamento de íliopsoas & $47,73 \%$ & $50,94 \%$ \\
Encurtamento de reto femoral & $36,36 \%$ & $35,85 \%$ \\
Teste "sentar e alcançar" & $24,4 \pm 5,7$ & $20,9 \pm 6,8 * *$ \\
\hline$*$ p $<0,05 ; * *$ p $<0,01$ & &
\end{tabular}


Conclusão: A hiperlordose lombar foi o desvio postural com maior prevalência nesta amostra. Observou-se um índice maior de dorsocurvo e hiperlordose cervical no Grupo B. Estas alterações estão relacionadas com desequilíbrios musculares, que podem persistir muitas vezes para a fase adulta.

\section{TRPO-20 EFEITOS DO EXERCÍCIO FÍSICO DURAN- TE A GESTAÇÃO NA SEGURANÇA DO RECÉM-NAS- CIDO}

Santos I.A., Carballo M.T., Oppermann M.L., Ramos J.G., Mengue S.S., Schmidt M.I.

PPG Epidemiologia e Dept. Ginecologia e Obstetrícia-FAMED-UFRGS; Dept. Estatística-UFRGS, Hospital de Clínicas de Porto Alegre

Objetivos: Avaliar os efeitos de um programa de exercício físico em gestantes pré-obesas, na segurança do recém-nascido em relação ao baixo peso de nascimento, escore Apgar e prematuridade do recémnascido. Métodos: Noventa e duas gestantes com idade $\geq 20$ anos, sem história prévia de diabetes, não fumantes, índice de massa corporal (IMC) pré-gravídico estimado de $25-30 \mathrm{~kg} / \mathrm{m} 2$, idade gestacional $\leq 20$ semanas, que consentiram em participar e aderiram ao protocolo estabelecido no período ruim foram alocadas aleatoriamente para intervenção (programa de atividade física regular, com três sessões semanais de trabalho aeróbico a 50-70\% da frequiência cardíaca máxima, até $140 \mathrm{bpm}$ ) ou controle (grupos focais ou sessões de relaxamento semanal). As variáveis baixo peso foi definido como peso de nascimento $<2.500 \mathrm{~g}$; prematuridade como idade gestacional $<37$ semanas. A significância estatística das diferenças em freqüência do baixo peso e da prematuridade foi avaliada pelo teste Exato de Fisher. O escore Apgar foi analisado por teste Mann-Whitney. Resultados: Dados preliminares de 41 gestantes do grupo intervenção e 42 do grupo controle demonstram que os recém-nascidos não apresentaram diferenças importantes quanto ao baixo peso ao nascer $(4,9 \%$ vs. $4,8 \% ; \mathrm{P}=0,99)$; prematuridade $(4,9 \%$ vs. $2,4 \%$; $\mathrm{P}=0,62)$; ou escore Apgar no primeiro minuto (8,5 $\pm 1,32$ vs. $8,2 \pm$ $1,87 ; \mathrm{P}=0,88)$ ou no quinto minuto $(9,6 \pm 0,5$ vs. $9,4 \pm 0,6 ; \mathrm{P}=$ $0,15)$. Conclusão: Um programa de atividade física regular de trabalho aeróbico a 50-70\% da freqüência cardíaca máxima em gestantes com sobrepeso não mostrou efeitos adversos sobre o baixo peso de nascimento, a prematuridade e a vitalidade do recém-nascido.

\section{TRPO-22 A TREINABILIDADE DA FORÇA MUSCU- LAR EM IDOSAS PRATICANTES DE HIDROGINÁS- TICA}

Müller F.G. ${ }^{1}$, Puhlmann A.C. ${ }^{1}$, Lima W.C. de ${ }^{1}$, Pinto R.S. ${ }^{2}$, Kruel L.F.M. ${ }^{2}$

\section{1) UDESC - Florianópolis/SC, Brasil; 2) UFRGS - Porto Alegre/RS, Brasil}

Objetivou-se analisar os efeitos de um programa de treinamento de força muscular realizado na hidroginástica sobre a força máxima dinâmica de flexores horizontais do ombro em idosas. Foi realizado um tratamento experimental com a duração de 12 semanas, composto por 4 mesociclos de 3 semanas. Os mesociclos foram constituí- dos, respectivamente, por 4 séries de 15 repetições, 4 séries de 12 repetições, 5 séries de 10 repetições e 5 séries de 8 repetições do movimento de flexão horizontal do ombro, utilizando-se equipamento resistivo. A amostra foi composta por 27 idosas, divididas em 3 grupos, 2 grupos experimentais (GE) e um grupo controle (GC). As idosas já praticantes de hidroginástica foram divididas em dois GE: o GE1, formado por 10 idosas participantes de programa tradicional de hidroginástica; e o GE2, formado por 10 idosas participantes do programa de hidroginástica com ênfase no treinamento de força. $\mathrm{O}$ GC foi formado por 7 idosas não praticantes de hidroginástica. A avaliação da força máxima dinâmica antes e após o tratamento experimental foi realizada através do teste de 1RM no equipamento de musculação voador direto. A análise estatística foi realizada através de estatística descritiva, teste t de Student e análise de variância. O nível de significância adotado foi $\mathrm{p} \leq 0,05$. Os resultados demonstraram um incremento estatisticamente significativo na força máxima dinâmica apenas para o GE2. Ao final do tratamento experimental, o $\Delta \%$ para este grupo foi de $10,89 \%$, correspondendo a um $\Delta$ de $1,8 \mathrm{~kg}$ (média no pré-teste $=16,52 \pm 2,97 \mathrm{~kg}$; média no pós-teste $=$ $18,32 \pm 3,15 \mathrm{~kg}$ ). Pode-se concluir que a hidroginástica é uma atividade física adequada para o aumento da força máxima dinâmica de flexores horizontais do ombro em idosas, desde que seja efetuado um treinamento específico para esta variável.

\section{TRPO-23 INCIDÊNCIA DE INSTABILIDADE ESCA- PULAR EM TENISTAS}

Zago, C.

\section{IPA, Porto Alegre, RS, Brasil}

Muitos autores descrevem o papel da escápula como um componente vital para o arremesso. A fraqueza dos músculos estabilizadores da escápula altera seu posicionamento e seu funcionamento, determinando alteração no funcionamento dos músculos que se inserem na escápula, os músculos do manguito rotador. Objetivo: Este trabalho propôs-se, através de um estudo quase-experimental, verificar a incidência de instabilidade escapular nos tenistas, tendo como amostra um total de 30 tenistas. Metodologia: Os atletas foram examinados através da aplicação de um teste de força muscular para os músculos estabilizadores da escápula - serrátil anterior, trapézio médio, rombóides, trapézio inferior - e através da aplicação do teste de deslizamento lateral da escápula proposto por Kibler (1998). Resumo dos resultados: $83,33 \%$ dos atletas apresentaram instabilidade escapular; destes, 73,33\% apresentavam dor em alguma articulação, relacionada à prática do tênis e 53,33\% deles apresentavam dor no ombro. Conclusões: A incidência de instabilidade escapular é alta $(83,33 \%)$, e mesmo tendo uma musculatura aparentemente forte, há um desequilíbrio de forças dos músculos que estabilizam a escápula nestes atletas. A assimetria no deslizamento lateral da escápula, encontrada em $60 \%$ dos atletas analisados, associada aos testes de força muscular revelou que os músculos estabilizadores escapulares não estão com a força normal nos atletas pesquisados. A necessidade de estabilizar a escápula nos atletas de arremesso já é amplamente discutida na literatura internacional, porém mais estudos ainda precisam ser realizados com objetivo de validar estas técnicas de mensuração para que o fisioterapeuta disponha de critérios fidedignos para avaliar a performance dos músculos escapulares no atleta de arremesso. 


\section{TRPO-24 AVALIAÇÃO DA CONDIÇÃO FÍSICA DOS ÁRBITROS DA FEDERAÇÃO GAÚCHA DE FUTSAL}

Romano J.C., Mello M.R., Siqueira O.D., Crescente L.A.

LAFIMED - ULBRA - Canoas/RS

Objetivos: Verificar a condição física de árbitros da Federação Gaúcha de Futsal. Metodologia: Foram avaliados 36 árbitros, todos do sexo masculino, com idade média de 39,9 anos, que atuaram no Campeonato Gaúcho de Futsal 2001. A coleta dos dados foi realizada no mês de março do mesmo ano pela equipe do LAFIMED-ULBRA. As medidas antropométricas (peso, estatura e dobras cutâneas) foram utilizadas para calcular o IMC e estimar o \% de gordura e \% de massa magra. Os testes físicos aplicados foram: Dinamometria Manual e Flexibilidade (Banco de Wells). O desempenho foi avaliado pelos testes propostos pela FIFA: Teste dos 50 metros, Teste dos 200 metros e o Teste de Cooper. Resultados: Os resultados encontrados nas referidas variáveis foram: $\mathrm{IMC}=29 \pm 3,7$, Gordura $(\%)=17,8 \pm$ 3,5, Massa Magra $(\%)=82,2 \pm 3,5$, Dinamometria manual $(\mathrm{kg}-\mathrm{f})=$ $37 \pm 7,7$, Flexibilidade $(\mathrm{cm})=21,9 \pm 9,4$, Teste dos 50 metros (tem$\mathrm{po} / \mathrm{s})=8,4 \pm 1,4$, Teste dos 200 metros (tempo/s) $=37,4 \pm 6,9$, Teste de Cooper $(\mathrm{VO} 2 \mathrm{máx}, \mathrm{ml} / \mathrm{kg} / \mathrm{min})=34,1 \pm 9,1$. Conclusão: Através deste estudo verificou-se que com os testes e os dados coletados, um grupo muito pequeno de árbitros estariam aptos nas provas exigidas pela FIFA, pois os resultados alcançados pela maioria ficaram abaixo dos índices estabelecidos. Os dados indicam, portanto, a necessidade de implementar um programa de treinamento para melhoria da condição física dos árbitros da federação gaúcha de futsal, visando alcançar os índices mínimos exigidos para qualificação (atuação) desses profissionais.

\section{TRPO-25 LIMIAR ANAERÓBIO: CORRELAÇÃO EN- TRE TESTES DE CAMPO E DE LABORATÓRIO EM} ATLETAS DE FUTEBOL

Crescente L.A., Siqueira O.D., Cardoso M.

\section{LAFIMED/ULBRA - UNISINOS - CENESP/UFRGS - Porto} Alegre/RS

Objetivos: Verificar a associação do limiar anaeróbio encontrado em teste de campo e o limiar obtido em teste de laboratório na esteira rolante. Metodologia: Utilizamos 20 atletas de futebol profissional da segunda divisão regional, com faixa etária entre 20 e 34 anos. Os testes foram realizados em fevereiro de 2002 (início da temporada). Para a determinação do limiar anaeróbio utilizou-se o método metabólico (coleta de lactato).

O teste de campo (Sirtori) consiste em correr durante 6 minutos com uma velocidade fixa de $13,5 \mathrm{~km} / \mathrm{h}$ com coleta de uma gota de sangue ao final da corrida para medição de lactato. O limiar é predito por uma fórmula que corresponde a velocidade $\mathrm{em} \mathrm{km} / \mathrm{h}$. O teste em esteira rolante (Mader) é realizado com uma velocidade inicial de $3,0 \mathrm{~m} / \mathrm{s}(10,8 \mathrm{~km} / \mathrm{h})$ e incrementos de carga (estágios) a cada 3 minutos de $0,5 \mathrm{~m} / \mathrm{s}(1,8 \mathrm{~km} / \mathrm{h})$ até a exaustão com uma inclinação fixa de $1 \%$. Ao final de cada estágio é coletada uma gota de sangue para medição de lactato. A velocidade correspondente a produção de $4 \mathrm{mmol} / 1$ determina o limiar. Para determinação do lactato usamos o equipamento portátil "Accusport". A esteira rolante utilizada foi Imbramed atl. A estatística dos dados foi pela correlação Produto Momento de Pearson. Resultados: O quadro abaixo apresenta os resultados de magnitude e sentido da correlação entre os limiares expressos nos testes.

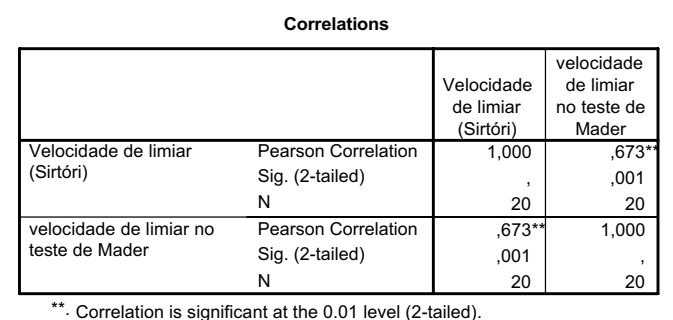

Conclusão: Encontramos uma correlação significativa e crescente entre os índices médios apresentados entre os testes de campo e de laboratório evidenciando que o teste de campo, por apresentar uma boa correspondência, pode ser aplicado na avaliação do limiar anaeróbio de atletas de futebol.

\section{TRPO-26 INFLUÊNCIAS DA ATIVIDADE FÍSICA COMO MINIMIZADORA DA DEPRESSÃO NA TER- CEIRA IDADE}

Vieira Z.M. ${ }^{1,2}$, Vidigal D.U. ${ }^{1}$

1. Clínica Urias Vidigal - Camboriú-SC; 2. NuPAF/CDS/ UFSC - Florianópolis-SC

Com o aumento da expectativa de vida, pode-se dizer que está surgindo uma nova preocupação entre profissionais da saúde na busca de melhor qualidade de vida, através da melhoria do bem estar psicológico, orgânico e físico para idosos, que pode ser adquirida com a prática constante e adequada de atividade física. Este estudo busca analisar entre os idosos que participam no programa de reabilitação de DCD (Doenças crônico-degenerativas) na Clínica Urias Vidigal em Camboriú-SC e que apresentam ou apresentaram sintomas de depressão, qual a contribuição da atividade física para o bem estar psicológico. A abordagem é qualitativa-descritiva, tendo como população 15 idosos acima de 60 anos, que possuem e/ou possuíram depressão e que participam de programa de reabilitação. A amostra foi composta por pacientes da Clínica Urias Vidigal em Camboriú$\mathrm{SC}$, sendo dez do gênero feminino e cinco do gênero masculino. A coleta de dados processou através de uma entrevista. Constatou-se através de análise de conteúdo que os prováveis motivos que propiciaram o quadro depressivo são em grande maioria as perdas (de cônjuges, de ente querido ou status social) e o esgotamento psíquico. Destacaram ainda as alterações decorrentes da depressão como: tristeza, irritabilidade, insônia, modificações orgânicas. Contudo, verificou-se que a atividade física melhorou tanto nos aspectos orgânicos quanto os psicológicos. Identificou-se que os idosos atualmente se sentem alegres com a idade, porém pouco valorizados. Desta forma a atividade física pode contribuir para minimizar os sintomas de depressão, garantindo aos idosos uma melhor saúde física e mental.

TRPO-27 IMPORTÂNCIA DA ATIVIDADE FÍSICA PARA OS PORTADORES DE DOENÇAS CRÔNICODEGENERATIVAS

Vieira Z.M. ${ }^{1,2}$, Vidigal D.U. ${ }^{1}$

1. Clínica Urias Vidigal - Camboriú-SC; 2. NuPAF/CDS/ UFSC - Florianópolis-SC

O número de idosos vêm crescendo nos últimos anos, no Brasil cerca de $8 \%$ da população ultrapassa a faixa de 60 anos. Devido ao processo de envelhecimento, juntamente com outros fatores que influenciam no desenvolvimento e no crescimento do ser humano, é 
possível verificar nos idosos a predominância de doenças crônicodegenerativas. O objetivo do estudo foi verificar em quais aspectos a atividade física tem sido importante na vida dos portadores de doenças crônico-degenerativas. O estudo foi de natureza descritiva, a população alvo deste estudo foram pacientes da Clínica Urias Vidigal em Camboriú-SC portadores de doenças crônico-degenerativas (hipertensão arterial, colesterol total, glicemia e depressão). A amostra envolveu 20 pacientes com idade entre 60 a 78 anos, fizeram parte do estudo as participantes das duas etapas da avaliação. Foi utilizado como instrumento a entrevista semi-estruturada as pacientes participaram quatro meses do programa, com exercícios supervisionados em cicloergômetro (cinco sessões semanais de 40 minutos, mais exercícios de resistência muscular local e alongamentos, com duração de aproximadamente $15 \mathrm{~min}$.); Os resultados evidenciaram que a atividade física auxiliou na melhor qualidade do sono, favoreceu a realização das atividades diárias, na melhoria na qualidade de vida, no controle do stress e proporcionou ampliação nos laços de amizade e maior vontade de viver possibilitou ainda um sentimento de felicidade e colaborando na manutenção da saúde. De acordo com os resultados a atividade física tem influenciado positivamente em aspectos ligados ao enfrentamento das dificuldades encontradas na vida diária próprias do envelhecimento e, mais especificamente, das doenças que possam surgir.

\section{TRPO-28 ADERÊNCIA A PROGRAMAS DE REABI- LITAÇÃO DE DOENÇAS CRÔNICO-DEGENERATI- VAS DE PESSOAS COM TRANSTORNO DEPRESSIVO}

Vieira Z.M. ${ }^{1,2}$; Vidigal D.U. ${ }^{1}$

\section{Clínica Urias Vidigal - Camboriú-SC; 2. NuPAF/CDS/ UFSC - Florianópolis-SC}

Os transtornos depressivos, devido sua prevalência e danos que acarretam, têm enorme importância como problemas de saúde pública, a reabilitação de Doenças Crônico-Degenerativas (DCD) vem sendo estudada com relação a sua aplicação no tratamento desses transtornos. A preocupação do estudo foi verificar os níveis de atividade física habitual, de depressão e aderência a programas de reabilitação de DCD de pessoas diagnosticadas com transtorno depressivo. Participam do estudo 240 pessoas que estavam realizando tratamento na Clínica Urias Vidigal em Camboriú-SC. A média de idade das pessoas avaliadas foi de 37,5 $\pm 14,0$ anos. Para a coleta de dados, além de um questionário aplicado para levantar informações sobre dados pessoais, nível socioeconômico e aderência à programas de reabilitação de DCD, foram também utilizados o IPAQ - Questionário Internacional de Atividade Física na versão 8.0 e o BDI - Inventário de Depressão (BECK, 1961). Houve uma predominância do gênero feminino, de pessoas pertencentes a classe socioeconômica média, com nível de instrução de médio, casadas, que trabalham e realizam tratamento na Clínica Urias Vidigal em Camboriú-SC. Quanto ao nível de atividade física habitual, houve uma predominância da inatividade física nove em cada dez homens e oito em cada dez mulheres, relataram nunca terem participado de programas de atividade física como parte do tratamento para depressão. A razão citada pela maioria das pessoas $(90,7 \%)$ para a não realização da reabilitação foi a falta de conhecimento. A maioria das pessoas apresentavam depressão há mais de três anos, o que caracterizava um estado crônico da doença. O tipo de tratamento relatado pela maioria das pes- soas $(96,4 \%)$ foi o farmacológico. Diante do exposto, conclui-se que homens e mulheres de nível socioeconômico médio, apresentam níveis mais graves de depressão e nível de participação em programas de reabilitação baixo e a maioria das pessoas praticantes de atividades físicas faziam a caminhada.

\section{TRPO-29 A PRÁTICA DA HIDROGINÁSTICA NA MEIA IDADE: INTERVENÇÃO AOS FATORES DE RIS- CO NO DESENVOLVIMENTO DE DOENÇA ARTE- RIAL CORONARIANA}

Soares T., Nasser J.

\section{Mestrado CDS/UFSC; Bolsista CAPES; Prof. Titular CDS/ UFSC}

Resumo: As doenças cardiovasculares são uma das principais causas de óbitos na sociedade moderna e entre elas, a doença arterial coronariana (DAC). Com base nesta consideração o objetivo deste estudo foi identificar alguns fatores de risco para o desenvolvimento de doença arterial coronariana em participantes do projeto de extensão da Universidade Federal de Santa Catarina (UFSC). Metodologia: Participaram da amostra 51 mulheres, com faixa etária entre 30 e 60 anos, praticantes de hidroginástica em águas profundas; utilizou-se para coleta de dados um questionário com perguntas abertas e fechadas relacionadas ao a) Histórico médico atual e familiar; b) Verificou-se a massa corporal $(\mathrm{kg})$, estatura $(\mathrm{cm})$, c) Relação cintura quadril (RCQ), d) Índice de Massa Corporal (IMC) e, e) Perímetros e dobras cutâneas considerando-os como indicadores de alguns fatores de risco. Resultados: Quanto ao a) 44,2\% apresentaram colesterol elevado, PA elevada, stress e ansiedade e $19 \%$ eram fumantes; c) 34,6\% referem-se a RCQ > 0,85; e d) 40,3\% apresentaram sobrepeso e 17,3\% obesidade I. Conclusões: Evidencia-se a importância do programa para que atenda aos componentes necessários ao desenvolvimento orgânico e funcional do corpo e possibilite influência positiva no comportamento em relação à saúde, proporcionando melhor estilo de vida às praticantes.

\section{TRPO-30 A ESTIMULAÇÃO RUSSA NO FORTALE- CIMENTO DO MEMBRO RESIDUAL DE AMPUTADOS} Signorelli M.C., Mazzucco M.C., Kurban E.

Laboratório de Eletrotermofototerapia - Depto. de Fisioterapia, Universidade Regional de Blumenau - Blumenau-SCBrasil

A pesquisa buscou por meio de uma revisão de literatura, estabelecer um protocolo para fortalecimento do membro residual em amputado transtibial proximal utilizando-se a eletroestimulação neuromuscular com modulação do tipo corrente russa. Este protocolo pode ser usado concomitante ou não à cinesioterapia, visando o treinamento muscular do coto, para uma melhor adaptação à prótese e retorno à deambulação e à prática de atividades físicas. Foi possível constatar que o nível de amputação transtibial predomina dentre todos os níveis de amputações de membro inferior, sendo que os grupos musculares que mais necessitam de fortalecimento são os extensores de joelho, adutores e extensores de quadril. Observou-se também, que a estimulação russa, pode ser um recurso terapêutico eficaz no fortalecimento muscular. Para que isso seja possível, o protocolo sugere os parâmetros mais recomendados referentes à freqüência de eletroestimulação; o tempo mínimo de contração e de 
repouso do músculo; o número mínimo de sessões, periodicidade e duração das mesmas; os grupos musculares a serem estimulados; a posição do paciente durante a aplicação da eletroestimulação e ainda situações em que a estimulação elétrica neuromuscular é contraindicada.

\section{TRPO-31 UTILIZAÇÃO DE SOFTWARE PARA CLAS- SIFICAR RISCO CORONÁRIO EM PREVENÇÃO PRI- MÁRIA A DAC \\ Perozin A.R., Cantos G.A., Jorge S., Silva C.S.M., Balém M.G., Waltrick A.C.A., Hermes E.M., Duarte M.F., Moser D.C., Menezes A.S., Waltrick C.D.A. \\ NIPEAD/Hospital Universitário/UFSC - Florianópolis-SC}

Este trabalho teve como objetivo classificar o risco coronariano, utilizando um software desenvolvido por um participante da equipe do Núcleo interdisciplinar de pesquisa, ensino e assistência à dislipidemia (NIPEAD). Os procedimentos utilizados nesse estudo englobaram os seguintes passos: primeiro foi definido o grupo de estudos, cuja população foi formada por 113 indivíduos, sendo 89 do sexo feminino $(79 \%)$ e 24 masculino (21\%), todos funcionários do Hospital Universitário. Posteriormente utilizou-se o software que relacionando a tabela de risco da the Second Joint Task Force of European and Societies on Coronary Prevention, com índice cintura quadril (ICQ), índice de massa corporal (IMC), dados clínicos e laboratoriais e também classificou individualmente cada participante no programa de prevenção primária para DAC (doença arterial coronariana). $\mathrm{O}$ dados desta pesquisa mostraram que dos 113 indivíduos analisados, 15,9\% eram fumantes, $8 \%$ diabéticos, 31,9\% hipertensos e $29,2 \%$ dislipidêmicos. A correlação conjunta desses dados mostrou ainda que 19,5\% estavam acima do peso ideal, 54,9\% tiveram o risco cintura quadril (RCQ) normal, 50,4\% risco cardíaco normal, $31,9 \%$ baixo risco, $16,8 \%$ risco moderado e $0,9 \%$ com alto risco cardíaco. Concluiu-se que o uso deste software otimiza o tempo de análise estatísticas, sendo capaz de reunir várias formas diferentes de avaliação de risco para DAC em um único sistema. Correlaciona também várias classificações esses fatores de risco entre si (IMC, ICQ, IRC, tabagismo, diabetes melitos, hipertensão arterial e colesterol total), criando uma classificação individualizada, e demonstra assim, a complexidade na aterogênese da doença coronariana.

\section{TRPO-32 BOM RETIRO UM MUNICÍPIO SAUDÁ- VEL? \\ Schnorr C. \\ NuCIDH/UFSC, SES/SUS, Florianópolis, SC - Brasil}

Buscou-se através deste trabalho avaliar antropometricamente uma amostra de habitantes do município de Bom Retiro (SC), com intervenção através do Projeto Município Saudável (PMS) da Secretaria Estadual de Saúde (SES/SUS), com aproximadamente 40 profissionais da área de saúde. As medidas utilizadas foram de massa corporal, estatura, perímetros da cintura e do quadril. Sucessivamente efetuou-se as relações do índice de massa corporal (IMC) e razão cintura/ quadril (RCQ), além da mensuração da pressão arterial (PA), realizada por enfermeiras da (SES/SUS), com o avaliado basicamente em repouso na posição sentada. Todas as medidas aconteceram em barracas no centro da cidade, onde as pessoas deslocaram-se voluntariamente para participar/consultar os agente do PMS. Além das medidas realizadas, informações sobre a importância de um estilo de vida ativo foram efetuadas por duas acadêmicas de Educação Física, sob orientação profissional. A amostra investigada e orientada foi de 211 pessoas ( 99 Homens e 112 mulheres), com média de faixa etária 40,67 $\pm 19,09$. A média do IMC para os adultos foi: Masculino (M) de 25,6 $\pm 3,7$; Feminino (F) 26,3 $\pm 5,1$. As médias da RCQ foram: (M) 0,89 $\pm 0,08$ e (F) $0,83 \pm 0,08$. No que se refere aos dados de (PA) verificou-se que as médias da pressão sistólica e diastólica ficaram dentro dos padrões de normalidade, respectivamente ordenadas em (M) $124,43 \mathrm{mmHg} \pm 23,03 / 78,33 \mathrm{mmHg} \pm 14,19$ e (F) $121,59 \mathrm{mmHg} \pm 23,12 / 73,76 \mathrm{mmHg} \pm 12,72$ (F). Conclui-se verificando que os indicativos referentes ao IMC representam para ambos os sexos uma classificação de sobrepeso. Na avaliação da RCQ os homens e as mulheres com menos de 30 anos também apresentaram risco baixo a moderado de adquirirem doenças crônicas degenerativas, sendo que, mulheres com mais 30 anos apresentaram-se com alto risco à saúde. Sabendo da eficácia da atividade física regular na prevenção e no tratamento de uma ampla variedade de distúrbios que afetam a sociedade contemporânea, diversas ações foram efetuadas com agentes do PMS em Bom Retiro.

\section{TRPO-33 ALTERAÇÕES NO CONSUMO MÁXIMO DE OXIGÊNIO DE DIABÉTICOS E HIPERTENSOS PARTICIPANTES DE UM PROGRAMA DE ATIVIDA- DE FÍSICA}

Honda S.S., Oliveira E.S.A., Loch M.R., Santos J., Duarte M.F.S.

Núcleo de Pesquisa em Atividade Física \& Saúde - NuPAF, CDS/UFSC - Florianópolis-SC - Brasil

O objetivo desse estudo foi verificar os efeitos de um programa de atividade física sobre o consumo máximo de oxigênio (VO2 máx.) em diabéticos e hipertensos adultos. Fizeram parte do estudo 22 indivíduos (59,04 \pm 9,06 anos), sendo 7 homens e 15 mulheres, que participaram regularmente do Programa de Atividade Física para Diabéticos e Hipertensos (PAFDH) da UFSC. Para estimar o VO2 máx. foi empregado o Teste de caminhada da milha (The Rockport Fitness Walking Test), aplicado no início do programa (T1) e após 16 semanas (T2). O PAFDH foi realizado 3 vezes/semana, com duração de $60 \mathrm{~min}$. (aquecimento, atividades aeróbias, exercícios de resistência muscular localizada e relaxamento). Para análise dos dados utilizou-se a estatística descritiva (média e desvio padrão) e o teste t de Student, comparando-se as médias do VO2 máx. entre o T1 e T2, considerando um nível de significância de $\mathrm{p}<0,01$. De acordo com os resultados, foi observado aumento significativo entre as médias do VO2 máx. entre T1 $(32,05 \pm 5,09 \mathrm{ml} / \mathrm{kg} / \mathrm{min})$ e T2 $(34,75 \pm$ $4,69 \mathrm{ml} / \mathrm{kg} / \mathrm{min})$. Controlando por sexo, nos homens as variações do VO2 máx. entre T1 $(31,32 \pm 6,85 \mathrm{ml} / \mathrm{kg} / \mathrm{min})$ e T2 $(33,65 \pm 6,01 \mathrm{ml} /$ $\mathrm{kg} / \mathrm{min}$ ) apresentaram-se estatisticamente significativas. Nas mulheres as diferenças entre as médias do VO2 máx. entre T1 (32,39 \pm $4,29 \mathrm{ml} / \mathrm{kg} / \mathrm{min})$ e T2 $(35,27 \pm 4,07 \mathrm{ml} / \mathrm{kg} / \mathrm{min})$ também foram consideradas significativas. Os resultados encontrados demonstraram que o PAFDH contribuiu para promover adaptações fisiológicas centrais e/ou periféricas capazes de aumentar significativamente o consumo máximo de oxigênio. O que por sua vez é extremamente importante, principalmente em se tratando de indivíduos com doenças crônicodegenerativas como diabetes e hipertensão arterial. 


\section{TRPO-34 EFEITO DE UM PROGRAMA DE ATIVIDA- DE FÍSICA SOBRE OS NÍVEIS DE FLEXIBILIDADE DE DIABÉTICOS E HIPERTENSOS ADULTOS}

Oliveira E.S.A., Loch M.R., Honda S.S., Santos J., Duarte M.F.S.

Universidade Federal de Santa Catarina - Centro de Desportos - Núcleo de Pesquisa em Atividade Física e Saúde-NuPAF - Florianópolis, SC, Brasil

O objetivo desse estudo foi verificar o efeito de um programa de atividade física sobre os níveis de flexibilidade de diabéticos e hipertensos adultos. Fizeram parte do estudo 23 indivíduos $(59,04 \pm$ 8,85 anos), sendo 7 homens e 16 mulheres, que participaram do Programa de Atividade Física para Diabéticos e Hipertensos (PAFDH) da UFSC. O PAFDH foi realizado 3 vezes por semana, com duração de 60 minutos por sessão (aquecimento, atividades aeróbicas, exercícios de resistência muscular localizada e relaxamento). Utilizouse o teste de Sentar e Alcançar para avaliar a flexibilidade do grupo, e as avaliações foram realizadas em um intervalo de 16 semanas (T1 e T2). Para a análise dos dados utilizou-se a estatística descritiva (média e desvio padrão) e o teste t de Student, considerando um nível de significância de $p<0,05$. De acordo com os resultados obtidos, foi observado um aumento significativo nas médias de flexibilidade da amostra entre T1 e T2, em ambos os sexos. Nos homens, a variação foi de $13,07 \pm 7,32 \mathrm{~cm}$ (T1) para 15,86 $\pm 6,91 \mathrm{~cm}$ (T2). Para as mulheres, a variação encontrada foi de $24,34 \pm 9,47 \mathrm{~cm}$ (T1) para $27,18 \pm 8,54 \mathrm{~cm}$ (T2). Mediante a análise dos resultados, verificouse alterações positivas nos níveis de flexibilidade dos diabéticos e hipertensos, contribuindo assim na melhora da aptidão física, desempenho diário, e conseqüentemente na qualidade de vida.

\section{TRPO-35 CORRELAÇÃO ENTRE O ÍNDICE DE CO- NICIDADE E OUTROS INDICADORES DE GORDURA CORPORAL: UM ESTUDO COM DIABÉTICOS E HI- PERTENSOS ADULTOS}

Loch M.R., Honda S.S., Oliveira E.S.A., Santos J., Duarte M.F.S.

Universidade Federal de Santa Catarina - Centro de Desportos - Núcleo de Pesquisa em Atividade Física e Saúde - Florianópolis, $\mathrm{SC}$, Brasil

O objetivo desse trabalho foi investigar a correlação entre o Índice de Conicidade (IC) e outros indicadores de gordura corporal. Fizeram parte do estudo 23 indivíduos $(59,04 \pm 8,85$ anos), sendo 7 homens e 16 mulheres, que participaram do Programa de Atividade Física para Diabéticos e Hipertensos (PAFDH) da UFSC. Os indicadores de gordura corporal utilizados foram o Índice de Massa Corporal (IMC), a Relação Cintura/Quadril (RCQ) e a estimativa do Percentual de Gordura (\%G). Para a tabulação dos dados utilizou-se o programa Excel para Windows e a determinação do coeficiente de correlação foi feita a partir da correlação linear de Pearson. Os resultados encontrados demonstraram uma boa correlação entre o IC e a RCQ $(r=0,79)$. Entretanto, com os outros indicadores de gordura corporal não foi encontrada correlação $(r=-0,08$ com IMC e $r=$ 0,00 com \%G). Os resultados sugerem que o IC tem uma abrangência parecida com a RCQ, ou seja, serve para a determinação da distribuição de gordura corporal e como indicador de fator de risco para a saúde.
TRPO-37 COMPORTAMENTO DO VO2 EM DIFERENTES NÍVEIS DE APTIDÃO AERÓBIA E TEMPOS DE ANÁLISE

Lima Silva A.E. ${ }^{1}$, Bertuzzi R.C.M..${ }^{1,2}$, Lotufo R.F. ${ }^{1}$, De Oliveira F.R. ${ }^{3}$

1) Instituto de Avaliação Física do Esporte - São Paulo; 2) Laboratório de Desempenho Esportivo - CENESP-EEFE-USP; 3) Depto. de Ciências Básicas e Sociais - UDESC - Joinville

Contrário ao disseminado, Kiss et al (2002) encontraram que jogadores juvenis de futebol com maior pico de velocidade (PV) e VO2max, tendem a apresentar maior VO2 nas cargas do teste progressivo em esteira (TPE). O tempo de análise pode influenciar o valor de VO2 em determinadas cargas (Robergs, 2001) e estas diferenças podem ser dependentes do nível de aptidão aeróbia. O objetivo deste estudo foi comparar a resposta do VO2 em um TPE, em diferentes níveis de aptidão e tempos de análises. Treze sujeitos fisicamente ativos (FIA), não atletas e quinze sedentários (SED) foram submetidos a TPE: vel. inicial de $4 \mathrm{~km} . \mathrm{h}-1$, incremento de $1 \mathrm{~km} . \mathrm{h}-1$ cada minuto até a exaustão, com medida direta do VO2 (Sensormedics ${ }^{\circledR}$ - Vmax séries 2000). Para a comparação do VO2 entre os grupos foram utilizados as médias das cinco últimas respirações $(5 R)$ e médias dos dez (10s), vinte (20s) e trinta (30s) segundos finais de cada estágio. ANOVA two way foi utilizada na comparação do consumo de oxigênio entre as quatro análises e entre os grupos em cada vel. O teste $\mathrm{t}$ foi aplicado para a comparação do PV e VO2max entre os grupos ( $\mathrm{p}<0,05)$. Os FIA apresentaram PV (km.h-1) e o VO2max (ml.kg-1.min-1) maior que os SED $(11,7+1,0 / 32,6+4,3$ versus $13,9+1,4 / 40,6+7,3$, respectivamente). Com o aumento da intensidade do exercício (> 8km.h-1) houve uma tendência de maiores valores de VO2 nos FIA, apesar de resultados inconsistentes nos diferentes tempos de análises. Estes achados podem ser devidos à cinética do VO2 em cargas abaixo ou acima do limiar ventilatório (Bearden et al, 2001), às diferenças na aptidão aeróbia e/ou dependente do protocolo escolhido.

\section{TRPO-39 ESTUDO DO METABOLISMO ENERGÉTI-} CO MUSCULAR EM ATLETAS POR ${ }^{31} P$-MRS

Santos, Maria Gisele ${ }^{(1)}$; González de Suso, Jose Manuel ${ }^{(2)}$; Moreno, Angel ${ }^{(3)}$; Cabanas, Miquel ${ }^{(4)}$; Arus, Carles ${ }^{(5)}$

(1) Universidade Federal do Paraná; (2) Centro de Alto Rendimento Esportivo de Barcelona; (3) Centro de Ressonância Magnética de Barcelona; (4) (5) Universidade Autônoma de Barcelona

Objetivo: Caracterizar as reservas energéticas de metabólitos fosforilados no músculo esquelético de atletas mediante espectroscopia

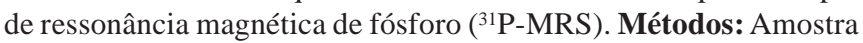
deste estudo foi formada por 14 atletas de alto nível do Centro de Alto Rendimento Esportivo (CAR, Sant Cugat del Vallés, Espanha). O padrão de metabólitos fosforilados foi medido no músculo vasto medial por ${ }^{31} \mathrm{P}$-MRS. A suplementação oral foi realizada durante 14 dias, na forma de $20 \mathrm{~g}$ de monohidrato de creatina. Os atletas foram determinados em dois grupos: placebo (maltodextrina) e suplementação com creatina. O protocolo de exercício foi realizado no interior do túnel de ressonância $(160 \times 52 \mathrm{~cm})$, a 60 ciclos por minuto para ambas as pernas. Resultados: Os resultados demonstraram diferenças estatisticamente significativas na PCr, pH e Pi, após o pe- 
ríodo de suplementação no grupo que recebeu suplementação com creatina. Conclusão: O exercício realizado pelos fundistas no CDP, permitiu detectar mediante ${ }^{31} \mathrm{P}-\mathrm{MRS}$, uma diminuição do consumo de $\mathrm{PCr}$ durante os períodos de exercício, devido à suplementação com creatina.

\section{TRPO-40 ANÁLISE DOS EFEITOS FISIOLÓGICOS DA SUPLEMENTAÇÃO DE CREATINA EM ATLETAS DE FUNDO E MEIO-FUNDO}

Santos, Maria Gisele ${ }^{(1)}$; González de Suso, Jose Manuel ${ }^{(2)}$; Moreno, Angel $^{(3)}$; Cabanas, Miquel ${ }^{(4)}$; Arus, Carles ${ }^{(5)}$

(1) Universidade Federal do Paraná; (2) Centro de Alto Rendimento Esportivo de Barcelona; (3) Centro de Ressonância Magnética de Barcelona; (4) (5) Universidade Autônoma de Barcelona

Objetivo: Analisar os efeitos fisiológicos da suplementação de creatina em quatorze corredores experientes de fundo e meio-fundo do Centro de Alto Rendimento Esportivo, Espanha. Métodos: Os atletas foram separados em dois grupos, conforme suas características físicas de peso, altura, índice de massa corporal e consumo máximo de oxigênio (VO2 max). Os grupos foram: placebo (maltodextrina) e suplementação com creatina ( $20 \mathrm{~g}$ de monohidrato de creatine). Ambos os grupos receberam suplementação oral por quatorze dias e mantiveram suas rotinas regulares de treinamento. O consumo máximo de oxigênio (VO2max), tempo para a fadiga e concentração de lactato sanguíneo foram medidos para a análise do efeito da suplementação oral de creatina. O consumo máximo de oxigênio foi medido através do protocolo de Daniel \& Daniel (1992) e o tempo para fadiga foi determinado pelo último estágio em que os atletas completaram o protocolo. Resultados: Não foram encontradas diferenças significativas no VO2máx e tempo para fadiga entre as condições de pré e pós-teste no grupo 1 . O lactato sanguíneo também não foi alterado significativamente, mas apresentou resultados níveis de significância "borderline" ( $\mathrm{p}=0,060)$. Conclusão: A suplementação oral de creatina, não interfere nas variáveis selecionadas neste estudo.

TRPO-41 CORRELAÇÃO ENTRE DOR LOMBAR E A PERCEPÇÃO SUBJETIVA DO ESTADO ATUAL DE SAÚDE EM MULHERES IDOSAS

Ilha P.M.V.', Menezes A.S., ${ }^{1,2}$, Souza G. de S. ${ }^{2,3}$, D'Agostini A. ${ }^{2,3}$, Duarte M. de F. da S. ${ }^{4}$

1) SEED/DR "08"/SE; 2) Mestrado CDS/UFSC; 3) Bolsista CAPES; 4) Profa. Titular CDS/UFSC. Centro de Desportos/ UFSC - Florianópolis/SC/Brasil

Objetivo: Identificar a associação entre e a dor lombar (DL) e a percepção subjetiva do estado atual de saúde (PSEAS) de mulheres idosas. Métodos: A amostra, selecionada por conveniência, foi composta por 61 mulheres com idades acima de 59 anos $(x=68,15+$ $5,19)$, participantes de um programa de extensão oferecido pelo Centro de Desportos da Universidade Federal de Santa Catarina. A coleta de dados foi realizada mediante aplicação de um questionário autoadministrado. Para análise estatística dos dados foi utilizada a medida de associação do Qui-quadrado, além da estatística descritiva (freqüência relativa) adotando-se um nível de significância de $\mathrm{p}<0,05$. Resultados: A variável percepção subjetiva do estado atual de saúde não apresentou associação estatisticamente significativa com a variável dor lombar. Descritivamente, pode-se observar que 60,7\% da amostra classifica o seu estado atual de saúde como bom $(\mathrm{n}=30)$, muito bom $(n=6)$ ou excelente $(n=1)$. Conclusão: Apesar da variável dor lombar estar relatada na literatura como sendo um fator que pode interferir diretamente na saúde, pode-se concluir, neste estudo, que a influência na PSEAS não foi observada e que a maioria da amostra classificou seu estado atual de saúde como bom, muito bom ou excelente apesar do incômodo da referida dor.

\section{TRPO-43 PERCEPÇÃO SUBJETIVA DO ESTADO ATUAL DE SAÚDE E SUA RELAÇÃO COM INDICA- DORES DE RISCO CARDIOVASCULAR EM MULHE- RES COM MAIS DE 59 ANOS}

Souza G. de S. e, Menezes A.S., Duarte M. de F. da S.

Universidade Federal de Santa Catarina, Florianópolis-SC, Brasil

O presente trabalho teve como objetivo identificar a associação entre a percepção subjetiva do estado atual de saúde e o diagnóstico por médico de hipertensão arterial (HA) e hipercolesterolemia (HC), reconhecidos como indicadores de risco cardiovascular. Para tal, foi selecionada por conveniência uma amostra de 47 mulheres, com idade acima de 59 anos $(x=66,57+4,92)$, participantes de um programa de extensão oferecido pelo Centro de Desportos da Universidade Federal de Santa Catarina. A partir da aplicação de um questionário auto-administrado, foi solicitada a classificação subjetiva do estado atual de saúde. Para análise dos dados foi utilizada, além da estatística descritiva (freqüência relativa), a medida de associação do Quiquadrado, adotando-se um nível de significância de $p<0,05$. Não foi encontrada nenhuma associação estatisticamente significativa entre nenhum dos indicadores analisados com a percepção subjetiva do estado atual de saúde. Analisando-se os dados descritivamente pode-se observar que a maioria das hipertensas $(61,7 \%)$ e das que possuem hipercolesterolemia (59\%) classificou a saúde como boa, muito boa ou excelente. Apesar de haver uma sugestão na literatura de que a classificação do estado atual de saúde sofre influência de indicadores de saúde, no presente estudo não houve concordância.

\section{TRPO-44 AVALIAÇÃO MORFO-FUNCIONAL EM ATLETAS DE TÊNIS DE CAMPO}

1-Monteiro J.A.D.M., Festugatto K., dos Santos R.T., Martins A.A.B.

1) Especialista em Fisiologia do Exercício - Escola Paulista de Medicina - UNIFESP - Departamento de Tênis-LIC/SC/Brasil

Objetivos: 1) Verificar o perfil de aptidão física de jovens atletas de tênis; e 2) quantificar através de uma avaliação morfo-funcional variáveis importantes para o desempenho atlético. Métodos: Foram avaliados onze atletas de tênis em pré temporada, que disputam torneios nacionais e internacionais com média de idade de 14 anos (10-17), peso $54,4 \mathrm{~kg}(33,1-69,1)$ e estatura $168 \mathrm{~cm}(139-185)$ e sexo $(\mathrm{M} / \mathrm{F})$. Os tenistas foram submetidos a testes de Potência aeróbia máxima (LÉGER et al. 1988), Potência anaeróbia máxima, média e índice de fadiga (Running-based Anaerobic Sprint Test - R.A.S.T), composição corporal, \% de gordura (DAURENBERG 198?), circunferências musculares e frequiência cardíaca máxima. Resultados: Os valores médios verificados foram: 1) consumo máximo de oxigênio (VO2 max 45,5ml.kg-1.mim-1.); 2) Potência anaeróbia máxima = 
$6,55 \mathrm{watts} / \mathrm{kg}$; potência média $=5,17 \mathrm{watts} / \mathrm{kg}$ e índice de fadiga $37,16 \%$; 3) Percentual de gordura $=18 \%$; e circunferências musculares $(\mathrm{D} / \mathrm{E})$ de coxa $=48,0-47,7$; perna $=33,4-33,4$; tórax 80,5; braço contraído $=26,3-25,3$; braço relaxado $=23,3-23,0$ e antebraço $=$ 23,6-22,7; 4) Freqüência cardíaca máxima (FC máx. 183bpm). Conclusão: Pode-se observar que publicações científicas sobre tênis em nosso pais são praticamente inexistentes, não havendo trabalhos de referência com tenistas brasileiros e muito menos protocolos específicos para atletas dessa modalidade. Dessa maneira fica havendo a necessidade de um número maior de trabalhos nessa área para a criação de um banco de dados específicos.

\section{TRPO-45 AMPLITUDE DE MOVIMENTO ARTICU- LAR, ALONGAMENTO E O TRABALHADOR}

Everton Silveira de Campos. evertonfloripa@yahoo.com.br*, Glaycon Michels. glaycon@ativanet.com.br**

* Programa de Pós-Graduação em Engenharia de Produção;

** Curso de Medicina UNISUL, Clínica CARDIOSPORT de Prevenção e Reabilitação, Florianópolis, SC, Brasil

Para desempenhar a maioria das tarefas cotidianas funcionais, assim como atividades ocupacionais, é necessário, amplitude de movimento articular (ADM) sem restrições e sem dor. Tendo isto como pressuposto este trabalho objetivou verificar o comportamento da ADM (amplitude de movimento articular) após aplicação de alongamentos estáticos durante dez sessões em trabalhadores das mais diversas áreas. Caracteriza-se com uma pesquisa experimental com "design" de um só grupo, com séries temporais. A amostra foi não probabilística acidental, constituindo-se de 15 pacientes que procuraram o serviço de fisioterapia de uma clínica de Florianópolis. A ADM foi verificada através do goniômetro da marca Pró Fisiomed possuindo dois braços de medição com fundo de escala de $180^{\circ}$, de precisão 2 graus. Para as medidas foi seguido o padrão, com modificações, de RICHARDSON \& IGLARSH. Os exercícios de alongamento foram utilizados como único recurso terapêutico, permitindo, desta forma, avaliar sua real contribuição para o ganho de ADM. Esta técnica foi aplicada em dez sessões de quarenta e cinco minutos, preferencialmente em dez dias úteis consecutivos, a um grupo de quinze pacientes do sexo masculino As ADM tiveram um aumento médio de $15 \%$ após o término do protocolo de alongamento. Acredita-se que a cinesioterapia de alongamento aplicada em dez sessões proporciona aumento da ADM, sugerindo, portanto, que o procedimento proposto seja uma alternativa viável para os trabalhadores que necessitam deste ganho. Palavras-chave: alongamento, cinesioterapia, ADM (amplitude de movimento), trabalho.

TRPO-46 MEDIDAS DE TORQUE DURANTE AVALIAÇÃO ISOCINÉTICA DE EXTENSÃO DO JOELHO EM CRIANÇAS

Lilian Gerdi Kittel Ries, d2lgkr@pobox.udesc.br*, Glaycon Michels.glaycon@ativanet.com.br**

* Programa de Pós-5Graduação em Engenharia de Produção Departamento de Prevenção, Avaliação e Reabilitação, UDESC; ** Programa de Pós-Graduação em Engenharia de Produção Curso de Medicina UNISUL, Clínica CARDIOSPORT de Prevenção e Reabilitação. Florianópolis, SC, Brasil Pesquisas com a aquisição de dados de força através da dinamometria isocinética em crianças são ainda escassas. Efeitos de forças mecânicas na musculatura que não esteja em perfeito equilíbrio podem interferir no crescimento e desenvolvimento da criança. O propósito deste estudo é determinar a média de pico de torque de extensores de joelho de crianças saudáveis e correlacionar esta variável com a idade, peso e altura. $\mathrm{O}$ pico de torque dos extensores de joelho foi avaliado em 9 crianças de 7 a 10 anos e 20 crianças de 11 a 14 anos através de teste isocinético usando um dinamômetro (Kin-Com). A avaliação foi realizada em várias velocidades funcionais $(60 \%$, $120 \%$ s e $180^{\circ}$ s), no lado dominante. Diferenças significantes foram estabelecidas nos picos de torque produzidos pelos extensores do joelho entre os grupos nas velocidades de $60^{\circ} / \mathrm{s}(\mathrm{p}=0,01045)$ e $180^{\circ} \%$ $\mathrm{s}(\mathrm{p}=0,01334)$. Existe diminuição nos picos de torque intragrupo com o aumento da velocidade, porém esta diferença não foi estatisticamente significativa. Nas três velocidades de teste de extensão de joelho, existe uma correlação significativa $(\mathrm{p}<0,05)$ entre a idade cronológica, peso e altura com o pico de torque. Estabelecendo-se parâmetros da performance muscular normal da criança em crescimento auxilia na prática clínica com a possibilidade de estabelecer correlações com a criança portadora de desordens músculo-esqueléticas. Palavras-chave: avaliação isocinética, extensão do joelho, pico de torque, crianças.

\section{TRPO-47 EFICIÊNCIA MECÂNICA MÉDIA DA PE- DALADA DE ATLETAS DE CICLISMO}

Cardoso T.R., Schutz G.R., Hubert M., Carminatti L.J., Della Giustina M., Nabinger E.

Universidade do Estado de Santa Catarina - UDESC Centro de Educação Física, Fisioterapia e Desportos - CEFID, Laboratório de Pesquisas em Biomecânica Aquática - LPBA Florianópolis, Santa Catarina - Brasil

O objetivo do trabalho foi determinar a eficiência mecânica média da pedalada de atletas de ciclismo através da dinamometria e da cinemetria. A pesquisa foi descritiva de campo. Foram medidas as forças tangenciais e normais, calculadas as forças transmitidas, perdidas e totais aplicadas ao pedal, chegando-se à eficiência mecânica da pedalada. Os testes foram realizados no Laboratório de Biomecânica do CEFID-UDESC. A população foi de atletas de ciclismo. A amostra foi de três atletas do sexo masculino de três níveis diferentes, sujeito 1 - Iniciante (campeonatos estaduais), sujeito 2 - Profissional veterano (ex-Seleção Brasileira) e sujeito 3 - Profissional (Seleção Brasileira). Os instrumentos utilizados foram: bicicleta do atleta, ciclo simulador CompuTrainer, pedal com célula de carga, programa SAD32, e sistema Peak Motus. Foi realizado um teste para cada sujeito pedalando em cadência de treinamento e competições. A carga, constante, correspondeu a sensação FORTE na Escala de BORG. Os resultados foram os seguintes: eficiência mecânica do sujeito $1=66,38 \% \pm 1,61$, do sujeito $2=63,52 \% \pm 0,39$ e do sujeito $3=64,9 \% \pm 1,95$. A eficiência média foi de $64,93 \% \pm 1,43$. Verificou-se que as eficiências dos três ciclistas foram parecidas, sendo que a maior foi a do ciclista iniciante, mostrando uma qualidade deste ou uma deficiência a ser melhorada pelos dois profissionais. Com o estudo conseguiu-se quantificar a eficiência mecânica da pedalada de ciclistas, trazendo novas perspectivas para a avaliação e otimização do desempenho de atletas e constituindo suporte científico para técnicos, treinadores e pesquisadores. 
TRPO-48 ANÁLISE DA VARIAÇÃO DE FORÇA NO MÚSCULO FLEXOR DOS DEDOS POR ESTIMULAÇÃO RUSSA: ESTUDO DE CASO

Bertoni A., Carbonera A.T., Soldi F., Roesler H.

Universidade do Estado de Santa Catarina - UDESC Centro

de Educação Física e Desportos - CEFID - Florianópolis, Santa Catarina - Brasil

A eletroterapia através da Estimulação Russa apresentou em algumas pesquisas bons resultados na área de fortalecimento muscular. Contudo, muitos artigos de pesquisa não registram as informações referentes aos parâmetros de estimulação, o que dificulta a reprodução de experimentos e, mesmo, a transposição dos resultados para a prática clínica. O estudo constou de uma aplicação com estimulação russa no membro superior não-dominante da musculatura flexora dos dedos, em um único indivíduo jovem, saudável e sedentário, onde objetivou-se verificar e quantificar, após 20 dias de estimulação, o ganho de força muscular através de parâmetros definidos de estimulação elétrica: frequiência de 54Hz, Ciclo ON/OFF 1:3 - 6/17 segundos, Rise e Decay 3 segundos e 20 contrações diárias. Foram realizadas coletas de perimetria e um teste de força. O teste de força, realizado no Laboratório de Biomecânica Aquática - UDESC, constou de um fixador articular projetado e desenvolvido para o estudo, uma célula de carga e um sistema com Placa de ponte de Wheatstom e condicionador de sinais CIO EXP BRIDGE e um conversor A/D CIO DAS 16 Jr ligados a um micro computador com o software SAD 32 (sistema de aquisição de dados). Os resultados foram os seguintes: aumento na perimetria do membro superior não-dominante em relação ao membro dominante, a analise de força mostrou aumento de $22,29 \mathrm{~N}$ no membro dominante e $44,54 \mathrm{~N}$ no membro não-dominante, apresentando assim um ganho de $13,7 \%$ a mais. Verificou-se que a variação de força no membro estimulado percentualmente foi maior, o aumento que ocorreu na perimetria demonstrou um aumento na área de secção transversal da musculatura pesquisada, podendo ser relacionada com um aumento de força evidenciado pela variação na analise de força do membro não-dominante que recebeu estimulação elétrica.

\section{TRPO-49 RELAÇÃO ENTRE O TEMPO DE BLOCO E O IMPULSO RESULTANTE DA TRACK START NA NATAÇÃO}

Schutz G.R., Hubert M., Cardoso T.R., Pereira S.M., Roesler H. Universidade do Estado de Santa Catarina - UDESC. Centro de Educação Física, Fisioterapia e Desportos - CEFID. Laboratório de Pesquisas em Biomecânica Aquática. Florianópolis, Santa Catarina - Brasil

Este estudo teve como objetivo verificar a relação entre o tempo gasto pelo nadador no bloco de partida e o impulso resultante em diferentes técnicas de execução da track start na natação. Participou um atleta que executou seis saídas para cada variação: Clássica (caracterizada por uma projeção anterior do Centro de Gravidade), Moderna (projeção posterior) e Texas (projeção centralizada). O estudo foi realizado nas instalações da piscina e do Laboratório de Pesquisas em Biomecânica Aquática do CEFID/UDESC, utilizando uma plataforma de força para aquisição de dados dinamométricos e temporais, um sincronizador de sinal sonoro para a saída e marcação no sistema de aquisição de dados. As saídas Clássica, Moderna e Texas apresentaram tempo de bloco médio de $0,80,0,91$ e 0,80 (s), e impulso resultante médio de $0,67,0,84$ e $0,75(\mathrm{~N} . \mathrm{s} / \mathrm{N})$, respectivamente. As diferenças entre as médias foram significativas ( $\mathrm{p}<0.01)$, pela ANOVA, para o impulso resultante e de mesma significância no tempo de bloco da saída Moderna às demais. O impulso resultante é o produto da força aplicada em cada instante pelo tempo de aplicação da mesma sobre o bloco, sendo assim, um maior tempo de bloco pode resultar em um maior impulso, como apresentado no maior valor médio obtido na variação Moderna. Esta média de tempo maior pode ser explicado pela maior distância em que a massa do corpo tem que se deslocar. Menores médias de tempo de bloco foram apresentadas para as saídas Clássica e Texas, sendo a primeira com a menor média de impulso resultante e a segunda com um resultado intermediário, originado de maiores valores das forças aplicadas, semelhantes à saída Moderna, embora, em uma menor média de tempo.

\section{TRPO-50 RELAÇÃO ENTRE O PICO MÁXIMO DE FORÇA E O TEMPO DE EXECUÇÃO DA VIRADA COM ROLAMENTO DO NADO CRAWL}

Hubert M., Schutz G.R., Cardoso T.R., Araújo L.G., Roesler H. Universidade do Estado de Santa Catarina-UDESC. Centro de Educação Física, Fisioterapia e Desportos - CEFID. Laboratório de Pesquisas em Biomecânica Aquática. Florianópolis, Santa Catarina - Brasil

O objetivo do trabalho foi identificar a relação do pico máximo de força aplicada pelo nadador na parede da piscina com o tempo de execução da virada com rolamento do nado Crawl. O estudo foi realizado na piscina e Laboratório de Pesquisas em Biomecânica Aquática do CEFID/UDESC, utilizando os dados obtidos através de dinamometria e cinemetria, caracterizando-se como pesquisa de campo, de natureza descritiva. Participou como amostra da pesquisa, um atleta nadador velocista federado, escolhido intencionalmente. Os dados foram coletados durante 12 execuções de viradas do atleta. Comprovando a importância do estudo das viradas, observou-se uma diferença de $0,3 \mathrm{~s}$ entre os tempos $(15 \mathrm{~m})$ da virada mais rápida e da mais lenta, o que se traduz em $59 \mathrm{~cm}$ de "vantagem" em uma prova de Natação, podendo esta diferença ser obtida apenas com o aperfeiçoamento da técnica de virada. Foi utilizada uma plataforma de força subaquática ROESLER (1997) do Laboratório, o programa de aquisição e processamento de dados SAD32 e uma câmera de vídeo super VHS $60 \mathrm{~Hz}$. A média dos tempos de virada foi de 8,11 s obtidos em $15 \mathrm{~m}$ (7,5 antes e 7,5 após a virada) e os valores de pico máximo de força variaram de 1,7 a 2,5 vezes o peso corporal do atleta. Para um nível de significância de 5\%, encontrou-se um coeficiente de correlação moderado e estatisticamente significante, indicando que maiores valores de pico máximo de força tendem a proporcionar viradas mais rápidas.

\section{TRPO-51 CAUSAS DO ABANDONO TEMPORÁRIO POR ATLETAS DE NATAÇÃO}

Freitas E.S., Pereira S.M.

Universidade do Estado de Santa Catarina - UDESC; Centro de Educação Física, Fisioterapia e Desportos - CEFID Florianópolis, $S C$ - Brasil

Na Natação de alto rendimento é muito comum a interrupção temporária da modalidade devido a problemas relacionados à saúde do atleta, com ênfase na interrupção relacionada as lesões. As lesões 
são um fator negativo nos treinamentos, pois prejudica os objetivos de todo um planejamento do trabalho anual do atleta. Este estudo teve por objetivo identificar as causas da interrupção temporária da prática da Natação por indivíduos atletas. Foi utilizado um questionário baseado nos questionários de ABREU (1993) e PASSOS (1997), que foram reestruturados e validados no quesito clareza por 5 atletas de Natação e 10 alunos da graduação de Educação Física do CEFIDUDESC. No quesito validade, os questionários foram avaliados por três profissionais da área da Educação Física. Os questionários foram aplicados em 31 atletas de Natação do Clube Doze de Agosto, com idades entre 13 e 24 anos, todos federados. Deste questionário foram respondidas duas questões, uma aberta e outra fechada sobre os motivos da interrupção temporária da prática da Natação. Os resultados foram discutidos e apresentados em forma de tabela, em que concluímos: dos 31 sujeitos da amostra 15 interromperam o treinamento de Natação e depois retornaram. Os principais motivos foram problemas de saúde (9) sujeitos, estudos (5 sujeitos) e cansaço (1 sujeito). Entre os problemas de saúde, as lesões foram as que mais afastaram temporariamente os nadadores. Entre as lesões citadas encontramos tendinite no cotovelo, tendinite no ombro, bursite no ombro, fraturas de braço e mão. Além das lesões outros problemas relacionados à saúde dos nadadores também foram citados, como asma provocada por exercício e outras doenças não especificadas. Vimos que as lesões foram as principais causas da interrupção temporária da modalidade, sugerindo que ações preventivas, como fortalecimento das estruturas em questão, devam fazer parte da rotina diária de treinamento.

\section{TRPO-53 ESTRESSE EMOCIONAL E ESTILO DE VIDA EM PORTADORES DE DOENÇAS CARDIOVAS- CULARES}

Steckling E., Andrade A., Silveira C.C.

Núcleo de Cardiologia e Medicina do Exercício - CEFIDUDESC; Lab. de Psicologia da Atividade Física - CEFID/ UDESC - Florianópolis-SC

Introdução: $\mathrm{O}$ aumento crescente no número de casos de doenças cardiovasculares está relacionado com o estilo de vida das pessoas, existindo uma íntima integração entre os fatores emocionais e os fisiológicos no desencadeamento de doenças cardiovasculares. Objetivo: Esta pesquisa tem como objetivo analisar o estresse emocional e o estilo de vida em indivíduos portadores de doenças cardiovasculares, especificamente coronariopatias e hipertensão arterial, quando da manifestação aguda da doença. Material e método: Este trabalho é uma pesquisa descritiva de campo. A amostra é constituída de 25 indivíduos, 13 (52\%) mulheres e 12 (48\%) homens, com idade média 62,31, desvio padrão de 6,23 (a faixa etária variou de 55 a 78 anos), que participam do Programa de Prevenção e Reabilitação Cardíaca, do Núcleo de Cardiologia e Medicina do Exercício, CEFID/UDESC. Resultados: Em períodos próximos a manifestação aguda da doença 53\% apresentaram altos níveis de estresse e 66\% apresentaram níveis de tensão elevados. Conclusões: Os resultados encontrados indicam que indivíduos que apresentam comportamento tipo A estão mais propensos a desenvolverem doenças cardiovasculares, demonstrando que antes da manifestação da doença, viveram altos níveis de estresse emocional, tensão, ansiedade, competitividade e perfeccionismo. Outro fator agravante é que estes indivíduos geralmente possuíam um estilo de vida sedentário e maus hábitos alimentares, caracterizado por uma dieta hipercalórica e alta ingestão de gorduras saturadas.

\section{TRPO-54 ESTRESSE EMOCIONAL E MANIFESTA- ÇÃO AGUDA DA DOENÇA CORONARIANA}

Duriex A., Silveira C.C., Andrade A., Carvalho T.

Núcleo de Cardiologia e Medicina do Exercício - CEFID-

UDESC; Lab. de Psicologia da Atividade Física - CEFID/ UDESC. Florianópolis-SC

Introdução: $\mathrm{O}$ estilo de vida exerce um impacto inegável no surgimento e evolução da cardiopatia isquêmica. Ocorre uma complexa interação entre os fatores emocionais e fisiológicos, sendo os problemas emocionais de relevante importância na fisiopatologia da cardiopatia isquêmica. Objetivo: Estabelecer a relação existente entre o estresse intenso e de difícil controle e o evento coronariano agudo. Material e método: Este é um estudo de campo, de natureza descritiva, com amostra do tipo casual estratificada. O cenário do estudo foi o programa de reabilitação cardíaca do Núcleo de Cardiologia e Medicina do Exercício, do CEFID-UDESC. A amostra foi composta por 20 pacientes, 12 homens $(60 \%)$ e 8 mulheres (40\%). A idade média foi de 59,35 anos, com desvio padrão de 7,57 (a faixa etária variou de 45 a 68 anos). O instrumento utilizado para a coleta de dados foi uma entrevista composta de um roteiro de questões semiestruturadas. Resultados: Na ocasião do evento coronariano observou-se que $80 \%$ colocaram-se como muito estressados e $20 \%$ como estressados, todos manifestando dificuldades no controle do estresse. Um ponto muito importante neste estudo é que $85 \%$ dos entrevistados afirmaram de maneira enfática que atravessavam problemas emocionais sérios, de difícil resolução antes da manifestação do evento. Conclusão: Os resultados sugerem que o estresse emocional intenso de difícil controle é um aspecto relevante no desencadeamento de eventos coronarianos. Considerar os fatores subjetivos, como a interpretação pessoal de situações significativas vivenciadas e o histórico de vida, é fator fundamental na compreensão da relação entre estresse e doença coronariana.

\section{TRPO-55 QUALIDADE DE VIDA DOS PROFESSORES INATIVOS X ATIVOS DA REDE ESTADUAL DE SAN- TA CATARINA}

Miriam Morriesen ${ }^{1}$, Mauricio Iost Guimarães. mauiogui@ linhalivre.net ${ }^{1,2}$, Glaycon Michels. glaycon@ ativanet.com.br ${ }^{1,3}$ Programa de Pós-Graduação em Engenharia de Produção; 1,2) Escola Superior de Turismo e Hotelaria de Florianópolis - ESTH; 1,3) Curso de Medicina UNISUL, Clínica CARDIOSPORT de Prevenção e Reabilitação. Florianópolis, SC, Brasil

Qualidade de vida pode ser definida como um conjunto de fatores individuais e sócio-ambientais, que caracterizam as condições em que vive o ser humano. Este estudo objetivou verificar a relação que há entre o professor ativo e o inativo quanto à qualidade de vida, envolvendo perspectivas de lazer, saúde, condições financeiras. Para tal, foi aplicado um questionário com 40 professores, do ensino médio e fundamental, com tempo de serviço e formação diversos. $\mathrm{O}$ grupo dos professores na ativa $(n=20)$, representados por $70 \%$ pelo sexo feminino e $30 \%$ do sexo masculino, o grupo dos aposentados 
$(n=20)$ de $100 \%$ sexo feminino Observou-se pelos resultados que os professores ativos sentem necessidade de ter mais lazer, preocupam-se com em adquirir bens e buscar mais conhecimentos, adotando um estilo de vida próprio, dependendo das suas condições. Quanto à definição sobre a qualidade de vida, o professor ativo avalia por meio contexto social, mais amplo, abrangendo a sociedade, algo mais macro. $\mathrm{O}$ professor aposentado apresenta mais resignação, um certo domínio da situação adotando um estilo de vida mais tranqüilo, preocupado com a saúde e o seu bem estar. Verifica-se que existe um campo a ser explorado na área da educação que é desenvolver no professor o "sentido de viver e aprender pela suas habilidade e capacidades, para ampliar o seu eu".

Palavras-chave: professor ativo, professor inativo, qualidade de vida, estilo de vida.

\section{TRPO-56 PARÂMETROS MORFOLÓGICOS DE ATLETAS DE FUTSAL DE SANTA CATARINA - CA- TEGORIA 14 A 17 ANOS}

Carminatti L.J., Benetti M., Della Giustina M.C., Giustina R.D., Dacar M., Pelissari M.F., Kalbusch V., Carvalho T.

Laboratório de Pesquisas Morfofuncionais - LAPEM-CEFIDUDESC/CENESP - Florianópolis-SC

Objetivo: Apresentar parâmetros médios das variáveis avaliadas durante competição que reúne as 12 melhores equipes do estado na categoria. Metodologia: Amostra de 55 atletas, de 5 equipes. Variáveis antropométricas: peso, estatura, dobras cutâneas, perímetros e diâmetros ósseos. Para o cálculo do somatotipo foi utilizado o modelo antropométrico de HEATH-CARTER e para estimativa da gordura percentual optou-se pela equação de SLAUGHTER (1988). Resultados:

\begin{tabular}{|l|r|r|r|r|}
\hline Variáveis & \multicolumn{1}{|c|}{ Média } & \multicolumn{1}{c|}{ DP } & \multicolumn{1}{c|}{ Mínimo } & \multicolumn{1}{c|}{ Máximo } \\
\hline Idade $(\mathrm{angs})$ & 16,07 & 0,81 & 14,00 & 17,00 \\
\hline Peso $(\mathrm{kg})$ & 65,55 & 7,00 & 53,10 & 90,80 \\
\hline Estatura $(\mathrm{cm})$ & 173,34 & 5,51 & 160,80 & 185,90 \\
\hline IMC $\left(\mathrm{kg} / \mathrm{m}^{2}\right)$ & 21,78 & 1,86 & 17,79 & 28,85 \\
\hline$\sum(\mathrm{TR}, \mathrm{SE}, \mathrm{SI}, \mathrm{PM}) \mathrm{mm}$ & 34,94 & 10,00 & 21,10 & 64,60 \\
\hline \% gordura & 13,55 & 3,20 & 8,35 & 22,32 \\
\hline Endomorfia & 2,59 & 0,83 & 1,30 & 4,99 \\
\hline Mesomorfia & 3,92 & 0,86 & 1,63 & 6,05 \\
\hline Ectomorfia & 2,97 & 0,90 & 0,64 & 5,13 \\
\hline
\end{tabular}

Pela ANOVA-ONE WAY não se constatou diferença significante entre as 4 posições de jogo $(\mathrm{p}<0,05)$. Conclusão: São dados preliminares que podem servir de referência para os profissionais que atuam na modalidade.

\section{TRPO-57 PARÂMETROS DE APTIDÃO FÍSICA DE ATLETAS DE FUTSAL DE SANTA CATARINA - CA- TEGORIA 14 A 17 ANOS}

Carminatti L.J., Benetti M., Della Giustina M.C., Giustina R.D., Bona E.D., Pelissari M.F., Kalbusch V., Carvalho T. Laboratório de Pesquisas Morfofuncionais - LAPEM-CEFIDUDESC/CENESP - Florianópolis-SC

Objetivo: Apresentar os resultados dos testes aplicados durante a competição que reúne as 12 melhores equipes do estado, a partir de uma bateria padronizada e referenciada ao rendimento esportivo do jovem atleta brasileiro. Metodologia: A amostra foi composta de 55 atletas do sexo masculino de cinco equipes que aceitaram participar da avaliação. Os testes de Aptidão Física foram aplicados de acordo com o protocolo descrito no Projeto Esporte Brasil (PROESP-BR/ GAYA, 2001), com exceção do teste de 9 minutos, que foi substituído pelo teste de estimativa da potência aeróbia (LÉGER et al., 1988). Resultados:

\begin{tabular}{|l|r|r|r|r|}
\hline Variáveis & \multicolumn{1}{|c|}{ Média } & \multicolumn{1}{c|}{ DP } & \multicolumn{1}{c|}{ Mínimo } & \multicolumn{1}{c|}{ Máximo } \\
\hline Idade (anos) & 16,07 & 0,81 & 14,00 & 17,00 \\
\hline Peso $(\mathrm{kg})$ & 65,55 & 7,00 & 53,10 & 90,80 \\
\hline Estatura $(\mathrm{cm})$ & 173,34 & 5,51 & 160,80 & 185,90 \\
\hline Abdominal 1 minuto (máx. rep.) & 49,81 & 8,57 & 33,00 & 64,00 \\
\hline Flexibilidade banco Wells $(\mathrm{cm})$ & 31,49 & 7,12 & 16,10 & 45,20 \\
\hline Salto horizontal $(\mathrm{cm})$ & 209,46 & 15,57 & 175,00 & 237,00 \\
\hline Arremesso medicinebol 2kg (cm) & 542,84 & 67,53 & 394,00 & 694,00 \\
\hline Agilidade quadrado 4X4m $(\mathrm{seg})$. & 5,11 & 0,34 & 3,53 & 5,66 \\
\hline Velocidade máxima 20 m $(\mathrm{m} / \mathrm{s})$ & 6,85 & 0,26 & 6,30 & 7,40 \\
\hline Potência aeróbia $(\mathrm{ml} / \mathrm{kg} / \mathrm{min})$ & 52,62 & 5,10 & 41,71 & 63,68 \\
\hline
\end{tabular}

Optou-se por fornecer os resultados dos atletas em conjunto para as quatro posições de jogo, uma vez que aplicou-se uma ANOVA-ONE WAY e não houve diferença significante entre elas ( $<<0,05)$. Em termos de resultado final na competição, as cinco equipes avaliadas apresentaram uma distribuição equilibrada. Conclusão: Considerase dados preliminares de referência para o FUTSAL de Santa Catarina. Sugere-se que novos estudos utilizem esta mesma bateria de testes com o objetivo de estabelecer um perfil de Aptidão Física da modalidade nesta categoria.

\section{TRPO-60 O DOPING NO HANDEBOL BRASILEIRO} Pelissari MF, Benetti M, Carminatti L, Giustina RD, Dacar M, Della Giustina MC, Kalbusch V, Guntzel, C, Carvalho T Laboratório de Pesquisas Morfofuncionais - LAPEM-CEFIDUDESC/CENESP - Florianópolis - Santa Catarina - Brasil

Introdução: No esporte competitivo constata-se uma obsessiva busca de resultados, o que muitas vezes pode levar à utilização do uso de substâncias e/ou procedimentos destinados a aumentar artificialmente a performance física e/ou técnica. Em nosso meio, em relação a esportes como o handebol, não existem relatos de investigação a respeito da utilização destes procedimentos, visando melhor rendimento em competições oficiais. Objetivo: Verificar a presença de substâncias proibidas em atletas de alto nível, praticantes de handebol. Material e métodos: Estudo descritivo, no qual foram avaliados 79 atletas de 20 a 35 anos de idade, do gênero masculino, de sete equipes (Adiee Florianópolis, Blumenau e Itajaí de SC, Americana/ SP, ACEPE/GO, ECP Recife/PE e Unisinos/RS), participantes do Campeonato Brasileiro de Handebol Adulto Masculino - 1a Divisão, evento realizado em abril de 2002, na cidade de Florianópolis Santa Catarina. Como instrumento de coleta dos dados foi utilizado o "ONTRAK TESTCUP 5" (desenvolvido pela empresa farmacêutica ROCHE, 1997). Trata-se de um recipiente próprio para a coleta de urina, no qual existem reagentes, os quais em contato com a amostra possibilitam a detecção (determinação qualitativa) de cinco (05) tipos de substâncias proibidas no contexto esportivo: anfetaminas, cocaína, THC, morfina e PCP. A leitura se faz através de uma tabela localizada no próprio recipiente de coleta. Resultados: Foram detectadas substâncias proibidas em quatro (04) atletas de 79 avaliados, representando 03,9\% do total. Conclusão: Constatou-se o uso de substâncias dopantes numa parcela significativa de atletas de alto nível do handebol nacional. Deste modo, fica demonstrada a necessidade de que, também em esportes nos quais tradicionalmente não tem existido uma preocupação em relação ao doping, seja adotada 
uma atitude de enfrentamento da situação, através do controle nas competições e de campanhas educativas junto aos atletas e membros das comissões técnicas.

\section{TRPO-61 ANTIDOPING NO CICLISMO "I DESAFIO DAS SERRAS"}

Della Giustina M.C., Della Giustina R., Carminatti L., Bona E.D., Willemann C., Kalbusch V., Carvalho T.

Laboratório de Pesquisas Morfofuncionais - LAPEM-CEFIDUDESC/CENESP - Florianópolis-SC

Introdução: Dentre as modalidades esportivas, o ciclismo tem sido a mais incriminada, talvez por sua busca incansável em detectar o uso de substâncias e ou métodos dopantes em praticamente todas as provas oficiais, com testes cada vez mais avançados e rigorosos, não omitindo do público seja quem for detectado positivo nestes testes. Objetivo: Verificar o possível uso de substâncias proibidas por ciclistas brasileiros de alto nível, em competição de grande dificuldade e importância. Material e método: Trata-se de um estudo descritivo, no qual foram avaliados 30 ciclistas participantes do "I Desafio das Serras" em Santa Catarina, sendo 15 (10 primeiros colocados e 5 sorteados aleatoriamente entre os participantes) da primeira e segunda etapa - subida da Serra Princesa Dona Francisca (28/3/02) e subida da Serra do Rio do Rastro (29/3/02). Como instrumento de coleta e análise dos dados foi utilizado o "ONTRAK TESTCUP5" (desenvolvido pela empresa farmacêutica ROCHE, 1997). Trata-se de um recipiente próprio para coleta de urina, no qual existem reagentes, os quais em contato com a amostra possibilitam a detecção (qualitativa) de cinco (5) tipos de substâncias proibidas no contexto esportivo: anfetaminas, cocaína, THC, PCP e morfina. A leitura dos resultados se faz através de uma tabela no próprio recipiente de coletas. Resultados: Apesar do ciclismo ser uma das modalidades mais incriminadas, neste trabalho não foi encontrado sequer um caso positivo, ao contrário de outras modalidades esportivas avaliadas recentemente pelo nosso grupo.

\section{TRPO-62 FLEXIBILIDADE E FORÇA MUSCULAR EM IDOSAS PRATICANTES DE HIDROGINÁSTICA OU OUTRAS ATIVIDADES FÍSICAS}

Puhlmann A.C., Müller F.G., Pelissari M.F., Lima W.C., Carvalho T.

\section{Laboratório de Pesquisas Morfofuncionais - LAPEM-CEFID- UDESC/CENESP - Florianópolis-SC}

Analisou-se a flexibilidade e a força muscular de flexores horizontais do ombro em idosas participantes de programas de hidroginástica e idosas participantes de outras atividades físicas - caminhada e ginástica. Foi realizada uma descrição comparativa entre os grupos em relação a estas variáveis. A amostra foi composta por dez indivíduos, divididos em dois grupos: o grupo 1, formado por cinco praticantes de hidroginástica pelo período mínimo de 6 meses, apresentando idade média de $65,40 \pm 2,88$ anos e valor de IMC correspondente a $27,60 \pm 2,32 \mathrm{~kg} / \mathrm{m}^{2}$; e o grupo 2 , formado por cinco praticantes de outras atividades físicas, apresentando idade média de $66 \pm 1,87$ anos e valor médio de IMC correspondente a 28,47 \pm $6,95 \mathrm{~kg} / \mathrm{m}^{2}$. a avaliação da força muscular máxima foi realizada através do teste de 1RM. Para determinar a flexibilidade do mesmo grupo muscular, foi utilizado o movimento do flexiteste (ARAÚJO, 1986). Os dados foram analisados por meio de estatística descritiva e pelo teste $\mathrm{t}$ de Student, sendo o nível de significância adotado foi $\mathrm{p}$ $<0,05$. Em relação ao grupo 1 o valor médio de força muscular encontrado foi $25,05 \pm 2,79 \mathrm{~kg}$ e o valor médio de flexibilidade correspondeu ao nível 1 da escala de avaliação de flexiteste. Em relação ao grupo 2, o valor médio de força muscular encontrado foi 17,85 \pm $5,04 \mathrm{~kg}$ e o valor médio de flexibilidade correspondeu ao nível $1 \mathrm{da}$ escala de avaliação do flexiteste. Foram encontradas diferenças, estatisticamente, significativas entre os grupos somente em relação à variável força muscular. De acordo com os dados obtidos, a prática de hidroginástica parece proporcionar maiores valores de força muscular máxima. Contudo, a flexibilidade apresenta valores similares para as praticantes de hidroginástica ou de outras atividades físicas. Pesquisas envolvendo amostras maiores possibilitariam conclusões mais representativas.

TRPO-63 MODIFICAÇ̃̃O DO STATUS DE ATIVIDADE FÍSICA DE PARTICIPANTES DO PROGRAMA SAÚDE EM FORMA

Lemos L, Garcia AS, De Bona ED, Carvalho T

Núcleo de Cardiologia e Medicina do Exercício - CEFIDUDESC; Clínica Cardiosport de Prevenção e Reabilitação; Unimed - Florianópolis-SC

Introdução: Um dos maiores objetivos de uma proposta de prevenção primária é o de elevar o grau de atividade física da população. $\mathrm{O}$ programa Saúde em Forma em Florianópolis, atua no sentido de incentivar e orientar para a prática de exercícios físicos. Objetivo: Avaliar o grau de atividade física dos indivíduos que foram atendidos pelo Programa Saúde em Forma. Método: Os indivíduos foram avaliados através de um questionário no qual constavam como possibilidades de resposta ser sedentário, moderadamente ativo, bastante ativo ou atleta. Foram avaliados 75 indivíduos, 34 do sexo masculino e 41 do sexo feminino, para verificação do grau de atividade física antes e após a intervenção do Programa Saúde em Forma. Com diferença de 03 meses entre as 02 avaliações. Resultados: $\mathrm{O}$ grupo inicialmente sedentário passou de 21 indivíduos (28\%), para 11 $(14,7 \%)$, com redução do sedentarismo em $13,3 \%$. Houve um acréscimo de $10,7 \%$ no grupo "moderadamente ativo", com este grupo passando de $48(64 \%)$ para $56(74,7 \%)$ dos indivíduos; o grupo de bastante ativos passou de $02(2,7 \%)$ para $04(5,3 \%)$ dos indivíduos. Não ocorreu nenhuma modificação no grupo de "atleta". Conclusão: A intervenção do programa mostrou-se efetiva em aprimorar o status de atividade física do grupo avaliado.

\section{TRPO-64 PEDALA FLORIPA (UDESC/UFSC) - CLÍ-} NICA DA BICICLETA

Della Giustina M.C. ${ }^{1}$, Carminatti L.J. ${ }^{1}$, Xavier G.N.A. ${ }^{1}$, Nahas M.V. ${ }^{2}$, Duarte M.F.S. ${ }^{2}$, Barros M.V.G. ${ }^{2}$, Teles C.D. ${ }^{2,3}$, Jeremias C. ${ }^{1,4}$

1) CEFID-UDESC - Florianópolis, SC, Brasil; 2) NUPAF/ UFSC; 3) Mestrando; 4) Graduando, bolsista

O projeto e a Clínica fazem parte das atividades do GRUPO CICLOBRASIL, grupo de pesquisa inscrito no CNPq, que também coordena várias atividades de extensão universitária com alcances municipais e estaduais em favor do uso da Bicicleta. A coordenação do grupo reúne professores do CEFID/UDESC e NUPAF/ UFSC. Objetivo: Conhecer características do usuário e do uso da bicicleta. Método: Aplicação de questionário durante o evento de 
extensão Clínica da Bicicleta I, realizado em 8 de dezembro de 2001, no trapiche da Av. Beira Mar Norte, em Florianópolis. Resumo dos resultados: Os entrevistados $(n=40)$ foram na sua maioria homens (65\%), entre 18 e 35 anos, mas também com uma boa participação de pessoas com idades superiores a 46 anos (25\%). Sobre nível educacional, $63 \%$ tem segundo grau completo e $13 \%$ menos escolaridade. Todos os entrevistados sabiam andar de bicicleta. O número médio de carros por residência foi de 1,4 (2,6 pessoas por carro). A média de bicicletas por residência foi $2,5(1,5$ pessoas por bicicleta). A média de 1.8 bicicletas por carro foi encontrada, o que fica próximo a estimativa do Ministério dos Transportes de $2: 1$. Setenta e um por cento dos entrevistados usam bicicleta para exercício e lazer, $14 \%$ usam como forma de transporte para o trabalho e $16 \%$ para a escola (mais de uma resposta poderia ser escolhida). Quanto à freqüência do uso, foi observado nessa população que a bicicleta é mais frequentemente utilizada para esporte e lazer, com 53\% de utilização de 2 a 4 vezes por semana e $23 \%$ em todos os dias. Os sujeitos da pesquisa consideraram que os maiores obstáculos para o uso da bicicleta como transporte foram a falta de infra-estrutura, ciclofaixas, estacionamentos seguros e chuveiros. As respostas sugerem que a idéia de ir ao trabalho de bicicleta já havia sido pensada antes. Conclusões: Atingiu-se uma população selecionada, devido ao local de realização do evento. Foi observado que nessa população a bicicleta é mais frequentemente utilizada para esporte e lazer.

\section{TRPO-65 PERFIL ANTROPOMÉTRICO DOS PARTI- CIPANTES DO PROGRAMA SAÚDE EM FORMA}

Souza CA, Monteiro JAAM, Lemos LS, Santos RTS, Correa KM, Carvalho T

Núcleo de Cardiologia e Medicina do Exercício- CEFIDUDESC; Unimed - Florianópolis

Objetivo: Avaliar o perfil antropométrico de participantes do Programa Saúde em Forma. Método: A amostra consistiu de 67 sujeitos, sendo 34 do sexo feminino e 33 do masculino, com idade entre 20 e 70 anos. Foi determinado o Índice de Massa Corporal (IMC), o Percentual de Gordura (método de dobras cutâneas) e a Relação Cintura/Quadril. Como instrumentos de medidas foram utilizados: balança e estadiômetro da marca Welmy, adipômetro da marca Slim Guide e fita métrica (Sanny). Para discussão dos resultados foi utilizado a estatística descritiva, com frequiência simples, média aritmética simples e percentil simples. Resultados: Dos avaliados, 55\% apresentavam IMC indicando excesso de peso, $86 \%$ mostraram-se com percentual de gordura acima do recomendado, sendo que $26,9 \%$ apresentavam excesso de gordura na área abdominal. Conclusões: A grande maioria dos sujeitos apresentaram algum grau de sobrepeso; o uso isolado do IMC não é suficiente para diagnosticar se há quadro de obesidade, e nem a sua gravidade, sendo interessante as medidas de dobras cutâneas e circunferências de cintura e quadril.

\section{TRPO-66 ARTES MARCIAIS EM FLORIANÓPOLIS, SC: MANIFESTAÇÕES DE COMPORTAMENTOS AGRESSIVOS EM SEUS PRATICANTES}

Araujo Junior R.M., Borgonovo S.M., Borgonovo S.M. CEFID/UDESC - Florianópolis/SC - Brasil

Atualmente, diversas notícias envolvendo praticantes de Artes Marciais, como brigas, campeonatos de vale-tudo e até filmes de ação, promovem uma visão unilateral das Artes Marciais, explorando a idéia de que estas estimulam e facilitam a violência e a agressão. Este estudo descritivo diagnóstico teve como objetivo geral Investigar as manifestações de comportamentos agressivos no contexto da prática de três Artes Marciais, Aikidô, Jiu-jitsu e Judô, em Florianópolis, SC. A amostra não-probabilística intencional, com características de estudo de caso, foi formada por 44 sujeitos, com idades entre 20 e 40 anos, do sexo masculino, sendo 15 praticantes de Aikidô, 16 de Jiu-Jitsu e 13 de Judô, de Florianópolis, SC. Utilizou-se o S.T.A.X.I., de Spielberger, e um Questionário de Experiências Pessoais na Prática das Artes Marciais. Foram utilizados o teste $\mathrm{t}$ de student e a estatística descritiva para tratamento dos dados. Através dos dados, observou-se que: $55 \%$ da amostra já havia sido agredida; os objetivos da maioria eram a filosofia de vida e o condicionamento físico proporcionados; melhora do autocontrole foi apontada como a principal contribuição filosófica desta prática. A amostra apresenta em relação à população brasileira (padrão): uma tendência menor a experimentar sentimentos de raiva relativamente intensos (e com menor freqüência), que em determinadas situações, podem ser controlados ou expressados em comportamentos agressivos; uma menor sensibilidade às criticas, que acabam por não despertar intensamente os sentimentos de raiva; menor tendência a manifestar os comportamentos agressivos. Estes resultados são considerados normais e corroboram com a literatura. Esta pesquisa possibilitou evidenciar que a agressividade não está ligada diretamente às artes marciais, ao contrário do que é divulgado nos meios de comunicação.

\section{TRPO-67 MELHORA DO DESEMPENHO CARDÍACO EM PACIENTES DE UM PROGRAMA DE REABILI- TAÇÃO CARDÍACA}

Koch A., Carvalho T.

Núcleo de Cardiologia e Medicina do Esporte-CEFIDUDESC; Clínica Cardiosport de Prevenção e Reabilitação Florianópolis-SC

Introdução: Estudos têm demonstrado que a aptidão física exerce grande influência na evolução da doença arterial coronariana (DAC). Daí a importância de um Programa de Reabilitação Cardíaca (PRC) planejado e estruturado. Objetivo: Observar a capacidade funcional cardiorrespiratória antes e após um PRC em pacientes com diagnóstico presente de DAC. Métodos: Foram estudados oito pacientes do sexo masculino portadores de DAC com idade média de sessenta anos que participam do programa de prevenção e reabilitação cardíaca da clínica Cardiosport da cidade de Florianópolis-SC. Efetuou-se a análise de dados dos Testes Ergométricos (TE) pré e pós PRC com intervalo em média de três meses entre os testes. As variáveis analisadas foram o duplo produto (FC x PAS) no segundo estágio do TE e a relação duplo produto máximo (DPmáx) e consumo máximo de oxigênio (VO2máx). Foi feita uma analise comparativa entre TE pré e pós. Resultados: Observou-se uma redução de $18,5 \%$ no duplo produto no segundo estágio do TE e uma redução de $20 \%$ da relação DPmáx/VO2máx ao compararmos TE pré e pós. Conclusão: Constatou-se uma importante melhora do desempenho cardiorrespiratório de cardiopatas isquêmicos em apenas três meses de PRC. 


\section{TRPO-68 FATORES QUE INFLUEM NA ADERÊNCIA À PROGRAMAS DE REABILITAÇÃO CARDÍACA}

Grechi G, Junctum GA, Carvalho T

Núcleo de Cardiologia e Medicina do Exercício - CEFID/

UDESC - Florianópolis-SC

Objetivo: Identificar fatores que influem na aderência a um programa de reabilitação cardíaca (RC). Método: Dentre os primeiros 40 cardiopatas isquêmicos, 28 homens, matriculados na RC em 2001, foram selecionados 14 (35\% do total), sendo 9 homens, que haviam deixado de participar do programa antes do prazo previsto. Foi utilizado um formulário, aplicado por via telefônica. Questionou-se sobre fatores que têm sido relacionados com a aderência à RC. Indagou-se a respeito da manutenção dos hábitos adquiridos no programa. Resultados: Prejudicaram a aderência: dificuldade de transporte (50\%), dificuldade de relacionamento com os outros pacientes $(37,5 \%)$, piora de co-morbidades $(25 \%)$ e falta de adaptação ao exercício físico (25\%), sendo citados a escassez de palestras formais e de informações sobre os benefícios do programa, além da pouca variedade de atividades. Como favoráveis à aderência houve referência à motivadora equipe multidisciplinar e à relação com pacientes com problemas semelhantes. Continuaram com exercícios físicos e controlando a alimentação 50\% dos indivíduos. Conclusões: Para uma maior aderência há necessidade de que sejam revistos aspectos sociais; emocionais; co-morbidades; e o próprio esquema de treinamento físico.

\section{TRPO-70 A INFLUÊNCIA DO EXERCÍCIO FÍSICO SOBRE O TRATAMENTO MEDICAMENTOSO NO CONTROLE DA HIPERTENSÃO ARTERIAL}

Hansen A, Carvalho T

Núcleo de Cardiologia e Medicina do Exercício - CEFIDUDESC - Florianópolis-SC

Introdução: A hipertensão arterial sistêmica (HAS) se constitui num grave problema de saúde pública, atingindo em torno de $20 \%$ da população brasileira adulta. Devido aos benefícios proporcionados com a prática regular de exercícios físicos, recomenda-se que programas de condicionamento físico sejam oferecidos aos portadores de HAS como recurso terapêutico. Objetivo: Analisar a influência do exercício físico sobre o tratamento medicamentoso no controle da HAS dos pacientes com hipertensão isolada (presença apenas de HAS) participantes do Programa de Reabilitação Cardiovascular do Centro de Educação Física Fisioterapia e Desportos (CEFID) da Universidade do Estado de Santa Catarina. Método: A pesquisa foi do tipo casual - comparativa, sendo a população composta de pacientes com HAS isolada que participaram das atividades do programa por mais de um ano. A amostra foi constituída de 13 pacientes hipertensos, sendo 10 do sexo feminino e 3 do sexo masculino no faixa etária de 50 a 75 anos. Os instrumentos utilizados para a coleta de dados se constituiu de um questionário e da análise dos prontuários para a obtenção de informações sobre o uso de medicamentos anti-hipertensivos. Resultados: $92 \%$ dos pacientes relataram alterações no tratamento medicamentoso. Verificou-se que $38 \%$ dos pacientes apontaram como principais alterações a retirada dos medicamentos e redução de dosagem. Em 16\% houve redução na quantidade de medicamentos. Conclusão: O programa de reabilitação cardiovascular, que conta com um programa de exercícios físicos, mostrou-se eficaz como tratamento não-medicamentoso da hipertensão arterial isolada, causando menor necessidade do uso de medicamentos anti-hipertensivos.

TRPO-71 INCIDÊNCIA DE DISTÚRBIOS MÚSCULOESQUELÉTICOS EM INDIVÍDUOS FREQÜENTADORES DE PROGRAMAS DE REABILITAÇÃO CARDÍACA EM FLORIANÓPOLIS

Mazzali R, Luz BS, Olivo CR, Zager M, Carvalho T

Núcleo de Cardiologia e Medicina do Exercício - CEFID/ UDESC; Clínica Cardiosport de Prevenção e Reabilitação Florianópolis-SC

Introdução: Tem sido descrito que distúrbios músculo-esqueléticos interferem na aderência a programas de reabilitação cardíaca (RC). Objetivo: Verificar a incidência de distúrbios músculo-esqueléticos em pacientes que freqüentam Programas de RC. Método: Trata-se de um estudo descritivo, no qual foram avaliados 61 indivíduos de ambos os sexos (20 mulheres e 41 homens), participantes dos Programas de RC desenvolvidos no Núcleo de Cardiologia do CEFID/ UDESC e Clínica Cardiosport, ambos funcionando em Florianópolis, sob a mesma coordenação. Para a coleta de dados foi usado um questionário fechado. Para análise estatística foi utilizado o programa Epiinfo 6.04. Resultados: Observou-se que 29,6\% eram ativos e $70,5 \%$ sedentários antes de iniciarem o programa; $67 \%$ apresentaram algum tipo de distúrbio músculo-esquelético, dos quais $83 \%$ apresentavam algum distúrbio antes de iniciarem e $70 \%$ adquiriram nos três primeiros meses, tendo ou não distúrbio prévio. Dentre estes, o problema de ordem músculo-esquelética interferiu significativamente nas atividades (p 0,0000001) em 69\% dos casos. A articulação mais acometida foi o joelho $(21,7 \%)$ seguida pela perna $(17,4 \%)$ e coluna lombar (13\%). A correlação distúrbios com sedentarismo apresentou $R R=1,32$, sem significância (p 0,38;). Conclusão: $O$ índice de distúrbios músculo-esqueléticos e a interferência que estes causam na efetividade e aderência a RC foi expressivo, sugerindo a necessidade de que uma sistemática abordagem preventiva seja adotada.

TRPO-72 INFLUÊNCIA DO PROGRAMA DE REABILITAÇÃO CARDÍACA NO DESEMPENHO DE PACIENTES COM DOENÇA ARTERIAL PERIFÉRICA

Garcia A.S., Simon A.C., Carvalho T.

Núcleo de Cardiologia e Medicina do Exercício - CEFIDUDESC - Florianópolis-SC

Introdução: A doença arterial periférica (DAP) traz grandes dificuldades nas atividades do dia-a-dia. Objetivo: Analisar as limitações do paciente nas atividades do cotidiano antes e após o programa de reabilitação cardíaca (PRC). Método: Através de um questionário aplicado pré e pós-reabilitação cardíaca foram analisados, em quatro pacientes, os itens mobilidade física e limitações (com as variáveis muito limitado, moderadamente limitado, pouco limitado e nada limitado), presença de dor em situações cotidianas, uma nota de auto-avaliação e medida da distância percorrida em uma sessão de reabilitação cardíaca. Houve também averiguação da desempenho físico através dos testes de 6' e da Milha. Resultados: Verificou-se melhora significativa referente à dor insuportável em $50 \%$ dos pacientes e à dor constante em $75 \%$ dos indivíduos, não se encontrando grandes melhoras na dor durante a caminhada e subida de escadas. Nos itens relacionados à mobilida- 
de e às limitações, houve melhora em 100\% dos indivíduos. Os pacientes relataram um grande progresso em todos os itens da autoavaliação, tendo demonstrado um aumento maior nas notas de lazer e saúde. A distância média de caminhada passou de 300 para $1.950 \mathrm{~m}$ em uma sessão de reabilitação cardíaca. Os testes comprovaram uma evolução proporcional ao tempo de participação no PRC. Conclusões: O PRC se mostrou de grande importância na reintegração dos pacientes às atividades de seu dia-a-dia, melhorando a qualidade de vida e incentivando o indivíduo a mudar seus hábitos para um estilo de vida saudável.

\section{TRPO-73 INFLUÊNCIA DO PROGRAMA REABILITA- ÇÃO CARDÍACA NO DESEMPENHO DE PACIENTES COM INSUFICIÊNCIA CARDÍACA CONGESTIVA}

Simon A.C., Garcia A.S., Carvalho T.

Núcleo de Cardiologia e Medicina do Exercício. Centro de Educação Física, Fisioterapia e Desportos. Universidade do Estado de Santa Catarina

Introdução: A insuficiência cardíaca congestiva (ICC) é um grande problema de saúde pública no Brasil, sendo a principal causa de internações hospitalares. Objetivo: Analisar as limitações do paciente nas atividades do cotidiano antes e após o programa de reabilitação cardíaca (PRC). Método: Através de um questionário aplicado pré e pós reabilitação cardíaca foram analisados, em sete pacientes, os itens mobilidade física e limitações (com as variáveis muito limitado, moderadamente limitado, pouco limitado e nada limitado), uma nota de auto-avaliação e a medida da distância percorrida. Houve também averiguação da desempenho físico através dos testes de 6' e da Milha. Resultados: Analisando as questões de mobilidade e limitações, constatou-se uma tendência aos pacientes se concentrarem no valor pouco limitado após a reabilitação. Os pacientes relataram uma grande melhora em todos os itens da auto-avaliação, tendo demonstrado um aumento maior nas notas de lazer e saúde. A distância média percorrida pelos pacientes passou de 993 para $2.514 \mathrm{~m}$ em uma sessão de RC. Através dos testes, foi observado que $71 \%$ dos pacientes apresentaram melhora de condicionamento após a reabilitação. Conclusão: Constatou-se considerável melhora em relação a aspectos que influenciam a qualidade de vida, como: sociabilização, lazer, melhora do desempenho físico, etc.

\section{TRPO-74 ANTIDOPING NO ATLETISMO JUVENIL}

Della Giustina R., Della Giustina M.C., Bona E.D., Willemann C. H., Maestri Z.E., Carminatti L., Carvalho T.

Laboratório de Pesquisas Morfofuncionais - LAPEM-CEFIDUDESC/CENESP - Florianópolis-SC

Introdução: Tem preocupado o crescente uso de substâncias utilizadas para melhorar a performance de atletas, inclusive entre os juvenis. Objetivo: Verificar o possível uso de substâncias proibidas por atletas juvenis, em campeonato estadual. Material e métodos: Este é um estudo descritivo, em caráter educativo, no qual foram avaliados 34 atletas participantes do XXV Campeonato Catarinense Juvenil de Atletismo, realizado em Criciúma, em maio de 2002. Foram analisados os primeiros e segundos colocados das diversas provas constantes da competição. Como instrumento de coleta e análise dos dados foi utilizado o "ONTRAK TESTCUP5" (desenvolvido pela empresa farmacêutica ROCHE, 1997). Trata- se de um recipiente próprio para coleta de urina, no qual existem reagentes, os quais em contato com a amostra possibilitam a detecção (qualitativa) de cinco (05) tipos de substâncias proibidas no contexto esportivo: anfetaminas, cocaína, THC, PCP e morfina. A leitura dos resultados se faz através de uma tabela no próprio recipiente de coletas. Resultados: Dentre os 34 testes, nove não foram válidos, sendo negativos para os grupos de substâncias analisadas todos os demais (25 testes). Conclusão: Não se constatou casos de dopping na amostra avaliada.

\section{TRTL-04 EFEITOS DE DIFERENTES INTENSIDA- DES DE EXERCÍCIO NOS NÍVEIS PLASMÁTICOS DO FATOR VON WILLEBRAND}

Salton G.D. ${ }^{1}$, Ribeiro J.L. ${ }^{2}$, Bandinelli E. ${ }^{1}$, Oliveira A.R. ${ }^{2}$, Roisenberg I. ${ }^{1}$

1) Departamento de Genética, IB, UFRGS, Porto Alegre, RS, Brasil; 2) Departamento de Educação Física, ESEF, UFRGS, Porto Alegre, RS, Brasil

O objetivo deste trabalho foi investigar a relação entre os níveis plasmáticos do fator von Willebrand ( $\mathrm{fvW}$ ) e diferentes intensidades de exercício físico. A amostra foi composta por 20 indivíduos saudáveis divididos em grupo $\mathrm{O}(\mathrm{n}=10)$ e grupo não $\mathrm{O}(\mathrm{n}=10)$, segundo o sistema sanguíneo ABO. Esses participantes foram submetidos a um protocolo de exercício cicloergométrico composto por três intensidades diferentes referentes a $10 \%$ abaixo do consumo de oxigênio (VO2) do 1을 limiar ventilatório (LV1), $10 \%$ abaixo do VO2 do 2 o limiar ventilatório (LV2) e à média entre o VO2 do 2o limiar e o consumo máximo de oxigênio (VO2máx) (AnMáx). As intensidades LV1 e LV2 são aeróbias leve e intensa, respectivamente, e a Anmáx é uma intensidade anaeróbia. Os níveis plasmáticos do fvW foram dosados por imunoeletroforese de Laurell utilizando anticorpo policlonal heterólogo. Nossos resultados mostram diferenças significativas entre os níveis de fvW antes e após o exercício para as três intensidades nos dois grupos de indivíduos: grupo $\mathrm{O}$ : LV1 $(\mathrm{t}=$ 4,74; $\mathrm{p}<0,001), \operatorname{LV} 2(\mathrm{t}=4,80 ; \mathrm{p}<0,001)$, AnMáx $(\mathrm{t}=7,09 ; \mathrm{p}<$ 0,001); grupo não $\mathrm{O}$ : LV1 ( $\mathrm{t}=4,65 ; \mathrm{p}<0,001), \operatorname{LV} 2(\mathrm{t}=4,67 ; \mathrm{p}<$ $0,001)$, AnMáx $(t=4,18 ; \mathrm{p}<0,001)$. Os resultados obtidos indicam que o exercício físico induz a liberação do fvW das células endoteliais tanto em intensidades aeróbias leves, quanto nas anaeróbias. Além disso, o grau desse aumento é dependente da intensidade do exercício, de modo que quanto mais forte a intensidade, maior o aumento dos níveis plasmáticos do fvW.

\section{TRTL-05 NÍVEL DE ACIDOSE SANGUÍNEA NO TES- TE DE WINGATE E EM EXERCÍCIOS SUPRAMÁXI- MOS DE 5 E 45 SEGUNDOS}

Dudek I.M., Antonnelli J.M., Colodel H.A., Esther E.F., Trindade-Junior Z., Zontta C., Sevilio M.N.O. Jr. Centro Universitário Positivo/UnicenP - Curitiba - ParanáBrasil

O objetivo deste estudo é comparar os níveis máximos de acidose sanguínea alcançadas durante o Teste de Wingate (30s) e em exercícios supramáximos de 5 e 45 segundos. Foram estudados 9 voluntários do sexo masculino de 27,22 $\pm 5,17$ anos e 7,57 $\pm 2,92$ percentual de gordura corporal. Os voluntários foram submetidos a três tipos de protocolos: $1 \times 5$ s, $1 \times 30$ s e $1 \times 45$ s, com intensidade 
subjetiva máxima, em um cicloergômetro com 1 semana de intervalo entre os protocolos. A concentração de lactato sanguíneo foi determinada através da análise (Accusport) de sangue $(20 \mu 1)$ obtidos do lóbulo da orelha em repouso e 3 minutos após o término do exercício. Utilizou-se neste estudo o teste t de Student $(\mathrm{p}<0,05)$ para a comparação entre os tratamentos. Não foi observada diferença estatisticamente significativa para as concentrações de lactato sanguíneo em repouso $\left(\mathrm{La} 5^{\prime \prime}=1,23 \pm 0,15 \mathrm{mmol} / 1\right.$; La 30" = $\left.1,29 \pm 0,24 \mathrm{mmol} / 1 \mathrm{e} \mathrm{La} 45^{\prime \prime}=1,44 \pm 0,35 \mathrm{mmol} / 1\right)$. Entretanto, as maiores concentrações de lactato sanguíneo foram observadas nos protocolos $1 \times 30$ s e $1 \times 45$ s $(\mathrm{La} 30 "=12,73 \pm 2,63 \mathrm{mmol} / 1$ e La 45" = $12,45 \pm 3,97 \mathrm{mmol} / \mathrm{l})$, que não foram estatisticamente diferentes entre si, mas significativamente maiores que o protocolo $1 \times 5 \mathrm{~s}(\mathrm{La}$ $\left.5^{\prime \prime}=5,05 \pm 1,24 \mathrm{mmol} / 1\right)$. Constatou-se que, os protocolos $1 \times 30 \mathrm{~s} \mathrm{e}$ $1 \times 45$ s são os mais adequados para se medir as concentrações máximas de lactato sanguíneo, entretanto, a escolha seria o 1 x30s por apresentar $15 \mathrm{~s}$ a menos de duração. Em relação ao protocolo 1 x $5 \mathrm{~s}$, apesar das concentrações serem estatisticamente menores em relação aos outros protocolos, apresentou uma concentração relativamente alta em comparação com o repouso, o que aponta para uma importante participação das vias glicolíticas no desempenho em exercícios com 5 s de duração.

\section{TRTL-21 MELHORA DA CAPACIDADE FUNCIONAL DE GESTANTES COM SOBREPESO ATRAVÉS DE UM PROGRAMA DE ATIVIDADE FÍSICA}

Santos I.A. ${ }^{2}$, Duncan B.B. ${ }^{1}$, Stein R. ${ }^{3}$, Fuchs S.C. ${ }^{1}$, Carballo M.T. ${ }^{2}$, Schmid, M.I. ${ }^{1}$

\section{1) Dept. Medicina Social - UFRGS; 2) PPG - Epidemiologia - FAMED-UFRGS; 3) Serv. Cardiologia HCPA/POA-RS}

Objetivo: Avaliar os efeitos do treinamento aeróbio sobre a capacidade funcional através de TE submáximo $\left(\mathrm{TE}_{\mathrm{Smax}}\right)$ em esteira em gestantes de baixo risco que apresentam sobrepeso. Métodos: Através de ensaio clínico randomizado estudou-se 92 gestantes hígidas com sobrepeso, com idade gestacional $\leq 20$ semanas e idade $\geq 20$ anos. 47 foram randomizadas para o grupo intervenção $(\mathrm{GI})$, realizando exercícios aeróbios 3 vezes por semana, 40 minutos por sessão, em uma freqüência cardíaca medida por freqüencímetro de 140bpm; 45 para o grupo controle (GC) recebendo cuidados prénatais convencionais. De forma cega, o $\mathrm{VO}_{2 \text { limiar }}$ foi identificado em $\mathrm{TE}_{\mathrm{Smax}}$ com protocolo de rampa uniforme por 2 cardiologistas proficientes no método 2 vezes, na entrada e após 12 semanas. 76 gestantes completaram o segundo teste, 72 ambos. A diferença entre $\mathrm{VO}_{2 \text { limiar }}$ após o programa foi avaliada utilizando análise de covariância com ajuste para idade gestacional e $\mathrm{VO}_{2 \text { limiar }}$ na linha de base. Resultados: Após o programa de treinamento, gestantes do grupo intervenção apresentaram $\mathrm{VO}_{2 \text { limiar }} 2,8 \mathrm{ml} / \mathrm{kg} / \mathrm{min}$ maior que no grupo controle $(\mathrm{P}<0,001)$. Houve aumento de $15 \%$ no $\mathrm{VO}_{2 \text { limiar }}(\mathrm{P}=0,001)$ entre o primeiro e o segundo $\mathrm{TE}_{\mathrm{Smax}}$ no GI e uma diminuição de $16 \%$ no GC $(P=0,001)$. Na segunda avaliação, as do grupo de intervenção tiveram uma probabilidade de apresentar capacidade física boa ou regular ( $\geq 21 \mathrm{ml} / \mathrm{kg} / \mathrm{min}) 4$ vezes maior que a do grupo controle (RR $=5,2$, IC95\% 1,2-22,.0) Conclusões Um programa de treinamento aeróbio de 12 semanas em gestantes produz um incremento significativo na capacidade funcional, avaliada pela medida do limiar anaeróbio determinado por TE.
TRTL-36 PREDIÇÃO DO SEGUNDO LIMIAR VENTILATÓRIO A PARTIR DO PICO DE VELOCIDADE EM TESTE PROGRESSIVO EM ESTEIRA

Lima Silva A.E. ${ }^{1}$, Lotufo R.F. ${ }^{1}$, De Oliveira F.R. ${ }^{2}$

1) Instituto de Avaliação Física do Esporte - São Paulo; 2)

Depto. de Ciências Básicas e Sociais - UDESC - Joinville

Os limiares de lactato e ventilatório (LV) são indicadores de capacidade aeróbia. Porém, estes métodos muitas vezes não são acessíveis, justificando a procura de abordagens alternativas. O pico de velocidade (PVE) em teste progressivo em esteira (TPE) é uma variável associada ao desempenho em provas aeróbias (Noakes et alii, 1990) e Limiar de Lactato (De Oliveira et alii, 1994). A FC submáxima (FCsub) é outro índice discriminante de aptidão aeróbia (De Oliveira, 1995). O objetivo do presente estudo foi verificar a possibilidade de estimar a velocidade do LV a partir da combinação do PV e FCsub. Vinte sujeitos ativos $(28,9 \pm 3,8$ anos) foram utilizados em um grupo de validação $(\mathrm{GV})$ e submetidos a TPE-horizontal, vel. inicial de $4 \mathrm{~km} . \mathrm{h}-1$, com incremento de $1 \mathrm{~km} . \mathrm{h}-1 / \mathrm{min}$ até a exaustão. A VLV foi identificada no ponto de aumento abrupto da relação VE/VCO2, acompanhada por uma queda na FCO2 expirado (LV2) e a FCsub foi medida na velocidade de $8 \mathrm{~km} / \mathrm{h}$ (FC8). A partir da análise de correlação múltipla foi gerada uma equação de regressão para o VLV2 (stepwise forward). Resultados do GV: VLV2 $=10,8 \pm 1,1 \mathrm{~km} . \mathrm{h}-1$, $\mathrm{PV}=13,7+1,6 \mathrm{~km} \cdot \mathrm{h}-1$ e FC8 $=139 \pm 12 \mathrm{bpm}$. A FC8 não entrou no modelo $(r=0,10)$. A equação resultante foi:

\begin{tabular}{|cc|}
\hline VLV2 $\left(\mathrm{km} . \mathrm{h}^{-1}\right)=2,511+\left(0,605 \times \mathrm{PV}, \mathrm{km} \cdot \mathrm{h}^{-1}\right)$ \\
$\mathrm{r}=0,87$ & $\mathrm{EPE}=0,55 \mathrm{~km} \cdot \mathrm{h}^{-1}$ \\
\hline
\end{tabular}

Os valores preditos de VLV2 no GVC não foram estatisticamente diferentes dos medidos $[\mathrm{r}=0,81$; EPE $=0,86 \mathrm{~km} \cdot \mathrm{h}-1(7,8 \%)]$. Assim, foram obtidas evidências de validade da predição de VLV2 a partir do PVE em grupos fisicamente ativos.

TRTL-38 LIMIARES VENTILATÓRIOS: DIFERENÇAS E ASSOCIAÇÕES ENTRE MÉTODOS DE IDENTIFICAÇÃO

Pires F.O. ${ }^{1}$, Lima Silva A.E. ${ }^{1}$, Lotufo R.F. ${ }^{1}$, De Oliveira F.R. ${ }^{2}$ 1) Instituto de Avaliação Física do Esporte - São Paulo; 2) Depto. de Ciências Básicas e Sociais - UDESC - Joinville A identificação do primeiro e segundo limiares ventilatórios (LV1 e LV2) é uma forma não invasiva de avaliação aeróbia. Porém, existem várias opções para identificá-los, restando dúvidas sobre os métodos mais consistentes em identificações positivas. $\mathrm{O}$ objetivo deste trabalho foi analisar as diferentes variáveis usadas na identificação de LV1 e LV2 e a associação entre eles. Vinte homens fisicamente ativos (28,9 $\pm 3,8$ anos; $176,4 \pm 6,8 \mathrm{~cm} ; 80,6 \pm 13,8 \mathrm{~kg}$ ) executaram protocolo em esteira rolante, vel. inicial ente 4 e $6 \mathrm{~km} . \mathrm{h}-1$ e incrementos de $1 \mathrm{~km} . \mathrm{h}-1$ cada minuto. Foram utilizados para as análises três valores médios de 20seg. Variáveis para LV1 = VE, VE/VO2, FEO2 e R; LV2 = VE, VE/ $\mathrm{VCO} 2$ e FECO2, identificadas por análise visual. A ANOVA e correlação múltipla resultaram $\left(\mathrm{n}=\mathrm{n}^{\circ}\right.$ de casos identificados):

\begin{tabular}{lllll}
\hline \multicolumn{2}{l}{ Critérios de LV1 $\left(\mathrm{km} \cdot \mathrm{h}^{-1}\right)$} & \multicolumn{2}{l}{ Critérios de LV2 $\left(\mathrm{km} \cdot \mathrm{h}^{-1}\right)$} \\
\hline VE1 & $7,2 \pm 0,7$ & $(\mathrm{n}=19)$ & $\mathrm{VE}_{2}$ & $11,4 \pm 1,5 \quad(\mathrm{n}=8)$ \\
${\mathrm{VE} / \mathrm{VO}_{2}}_{2}$ & $8,0 \pm 0,9$ & $(\mathrm{n}=16)$ & ${\mathrm{VE} / \mathrm{NCO}_{2}}$ & $10,1 \pm 1,0 \quad(\mathrm{n}=15)$ \\
$\mathrm{FEO}_{2}$ & $7,5 \pm 0,9$ & $(\mathrm{n}=15)$ & $\mathrm{FECO}_{2}$ & $10,1 \pm 1,0 \quad(\mathrm{n}=16)$ \\
$\mathrm{R}$ & $7,4 \pm 1,0$ & $(\mathrm{n}=18)$ & & \\
\hline
\end{tabular}

$\mathrm{Em} \mathrm{LV} 1 \mathrm{VE} \neq \mathrm{VE} / \mathrm{VO} 2$., no LV2 VE $\neq \mathrm{VE} / \mathrm{VCO} 2$ e FECO2 $(\mathrm{p}<$ $0,05)$. No LV1, as correlações significantes oscilaram entre $0,61 \mathrm{e}$ 
0,74 ; somente $\mathrm{R}$ não manteve correlação significante com as outras variáveis ( $\mathrm{r}$ entre 0,18 e 0,50). Em LV2, todas as associações são significantes, com r entre 0,88 e 0,97 . Recomenda-se cautela na utilização destes critérios como identificadores do mesmo fenômeno para a discriminação de aptidão aeróbia e prescrição de treinamento.

TRTL-52 CONSIDERAÇÕES SOBRE O USO DE REPOSITORES HIDROELETROLÍTICOS PARA PREVENÇÃO DA HIPOGLICEMIA NO DIABETES MELLITUS TIPO 1

Murara A., Carvalho T.

Laboratório de Pesquisas Morfofuncionais - LAPEM-CEFIDUDESC/CENESP - Florianópolis-SC

Introdução: Os diabéticos do tipo 1 praticantes de exercícios físicos desgastantes, necessitam adotar medidas que os mantenham equilibrados tanto hidroeletroliticamente, como em relação ao metabolismo glicídico, aspecto essencial, diante da iminente possibilidade da hipoglicemia, que se acentua com o exercício físico. Na prática, existem dúvidas sobre a indicação do uso freqüente de repositores hidroeletrolíticos com composição isotônica de carboidrato, para atletas portadores de DM tipo 1. Objetivo: Estabelecer a possível indicação do uso de bebidas esportivas para diabéticos. Método: Revisão bibliográfica sistemática para levantamento de demandas específicas do trabalho físico, seja com o objetivo de melhorar a performance ou somente a manutenção da homeostasia de diabéticos dependentes de insulina exógena; entrevistas com atletas diabéticos para verificação dos efeitos da bebida esportiva frente a esforço; desenvolvimento de diluições caseiras que possam substituir as bebidas esportivas industrializadas. Resultados: Tanto a revisão bibliográfica sistemática, como o preparo de substâncias caseiras, oferecem as condições necessárias para manter o diabético equilibrado durante a prática esportiva. As entrevistas comprovam que, na prática, o uso de tais bebidas a intervalos regulares e calculados mostra resultados satisfatórios. Conclusões: Os repositores podem se constituir em importante fonte exógena de carboidratos durante o esforço para diabéticos atletas; o uso de diluições caseiras, com fontes de carboidratos palatáveis e de custo acessível (açúcar de mesa, gelatina, glucose de milho, etc.) pode facilitar o acesso e garantir os benefícios a um maior número de diabéticos desportistas.

\section{TRTL-58 EFEITO AGUDO DO EXERCÍCIO FÍSICO AERÓBIO SOBRE A PRESSÃO ARTERIAL DE HIPER- TENSOS CONTROLADOS SUBMETIDOS A DIFEREN- TES VOLUMES DE TREINAMENTO}

Rebelo F.P.V., Benetti M., Carvalho T.

Núcleo de Cardiologia e Medicina do Exercício - CEFIDUDESC. Clínica Cardiosport de Prevenção e Reabilitação Florianópolis-SC

Introdução: Um programa de condicionamento físico tem sido freqüentemente recomendado como uma conduta importante no tratamento não farmacológico da hipertensão arterial. Tem sido verificado que não somente o exercício crônico, mas também uma única sessão de exercício físico provoca diminuição na Pressão Arterial (PA). Objetivo: Analisar o efeito agudo de duas sessões de exercício físico aeróbio de diferentes volumes na eventual queda pressórica observada no período pós-exercício; e se a duração da sessão poderia influenciar na magnitude dessa hipotensão. Métodos: 23 indivíduos hipertensos controlados (17 homens e 6 mulheres), com idade entre 35 e 65 anos, praticantes de atividade física regular, foram submetidos a uma sessão controle e duas sessões experimentais de exercício dinâmico em cicloergômetro com 25 e 45 minutos de duração, a $75 \%$ da frequiência cardíaca máxima. Os valores de pressão arterial sistólica (PAS), pressão arterial diastólica (PAD) e frequiência cardíaca (FC) foram medidos no período pré-exercício (após 15 minutos de repouso) e no período pós-exercício $\left(1^{\circ}, 5^{\circ}, 10^{\circ}, 20^{\circ}\right.$ e $30^{\circ}$ minuto de recuperação) tanto nas sessões experimentais como na sessão controle. Resultados: Convergem para uma diminuição nos níveis de PA no período de recuperação nas sessões experimentais, quando comparados a sessão controle. O exercício físico com 45 minutos de duração proporcionou queda mais acentuada da PAS e PAD que na sessão de 25 minutos, quando comparadas a sessão controle. Em relação a comparação entre as duas sessões experimentais, observou-se queda significativa $(\mathrm{p}<0,05) \mathrm{da}$ PAS no $1^{\circ}$ minuto de recuperação enquanto que a PAD não apresentou diferença significativa. Conclusões: A magnitude e a duração do efeito hipotensor do exercício físico parecem ser maiores após uma sessão de maior volume quando comparados a uma sessão de menor volume, verificando-se assim, a influência da duração do exercício na hipotensão pós-exercício.

\section{TRTL-59 EFEITOS DA SUPLEMENTAÇÃO DE HMB SOBRE O LDL-COLESTEROL, FORÇA E COMPOSI- ÇÃO CORPORAL}

Coelho C.W., Carvalho T.

Universidade Tiradentes - Unit - Aracaju, SE'; Laboratório de Pesquisas Morfofuncionais - LAPEM-CEFID-UDESC/CE$N E S P^{2}$

Tem sido descrito que o hidróxido metil butirato (HMB), um metabólito da leucina, pode aumentar a massa magra e os ganhos em força muscular e contribuir para reduzir o LDL-colesterol. Objetivo: Estudar o efeito do HMB na correção da dislipidemia e na composição corporal e força muscular de indivíduos com deslipidemia. Métodos: A amostra consistiu de 12 homens com idades entre 50 e 72 anos com relação do Colesterol Total e HDL-colesterol > 4,5 foram randomicamente designados num estudo duplo-cego para a ingestão de cápsulas de placebo ou cápsulas contendo HMB (3g/dia) durante 4 semanas de estudo. Os pacientes foram submetidos a um programa de exercícios 5 vezes por semana (3 dias de exercícios aeróbios e 2 dias de exercícios contra resistência). Amostras de sangue, teste de uma repetição máxima (1RM), gordura corporal e massa magra (dobras cutâneas/ ISAK) foram mensurados no início e no final de 4 semanas de estudo. Resultados: Os resultados mostraram diferenças significativas $(\mathrm{p}=$ 0,01 ) entre o pré e o pós testes para o LDL-colesterol - $172 \pm 11,7 \mathrm{mg} /$ dl e $123 \pm 9,1 \mathrm{mg} / \mathrm{dl}$ - respectivamente e houve um aumento de $6 \%$ na massa magra $(35,3 \pm 1,98 \mathrm{~kg}$ e $37,68 \pm 2,42 \mathrm{~kg}$ ) no grupo que foi suplementado com HMB. A força também aumentou significativamente ( $\mathrm{p}$ $<0,05)$ nos três exercícios testados como segue: (a) leg press $(7 \pm$ $1,2 \mathrm{~kg}$ e $8,8 \pm 1,4 \mathrm{~kg}$ ); (b) puxada por trás $(5,5 \pm 0,1 \mathrm{~kg} \mathrm{e} 7 \pm 0,9 \mathrm{~kg}$ ); (c) rosca bíceps $(5,5 \pm 1 \mathrm{~kg} \mathrm{e} 7 \pm 1 \mathrm{~kg})$ no grupo com HMB. O grupo placebo não demonstrou diferenças significativas no LDL-colesterol e massa magra, mas houve diferenças significativas entre o pré e o pós testes de dois exercícios, o leg press $(6,5 \pm 0,7 \mathrm{~kg}$ e $7,8 \pm 0,9 \mathrm{~kg})$ e a puxada por trás $(4,3 \pm 0,4 \mathrm{~kg}$ e $6,1 \pm 0,6 \mathrm{~kg})$. Conclusão: A suplementação de HMB em combinação com exercícios proporcionou significativas redução de LDL-colesterol e ganho de massa magra e força. 